Invited review

Special Issue of Journal of Experimental Botany:

Essential trace metals: micronutrients with large impact

\title{
Plant iron nutrition in the long road from soil to seeds
}

Irene Murgia* ${ }^{1}$, Francesca Marzorati ${ }^{2}$, Gianpiero Vigani ${ }^{3}$ and Piero Morandini ${ }^{2}$

${ }^{1}$ Dept. Biosciences, University of Milano, Italy; ${ }^{2}$ Dept. Environmental Science and Policy, University of Milano, Italy; ${ }^{3}$ Plant Physiology Unit, Dept. Life Sciences and Systems Biology, University of Torino, Italy.

author for correspondence: Irene Murgia irene.murgia@unimi.it.

authors email addresses:

irene.murgia@unimi.it, francesca.marzorati1@unimi.it,gianpiero.vigani@unito.it, piero.morandini@unimi.it.

\section{Highlight}

The interactions between rhizosphere microbiota and plants, the seeds loading with iron represent relevant lines of research, also in wild crop relatives, for the full understanding of plant iron nutrition.

(C) The Author(s) 2021. Published by Oxford University Press on behalf of the Society for Experimental Biology. All rights reserved. For permissions, please email:

journals.permissions@oup.com 


\section{Abstract}

Iron (Fe) is an essential plant micronutrient since photosynthesis, respiration, the scavenging of reactive oxygen species and many other cellular processes depend on adequate Fe levels. Nonetheless, non-complexed Fe ions can be dangerous for cells, as they can act as a pro-oxidant. Therefore, plants possess a complex homeostatic control system for safely taking up Fe from the soil, transporting it to the various cellular destinations and for its subcellular compartmentalization. At the end of the plant's life cycle, maturing seeds are loaded with the required amount of Fe for germination and early seedling establishment. In this review, we discuss recent findings on how the microbiota in the rhizosphere influence and interact with the strategies adopted by plants to take up iron from the soil. We also focus on the process of seed loading with Fe and take into account the Fe metabolism in wild crops' relatives. These aspects of plant Fe nutrition can represent promising avenues for a better comprehension of the long road of Fe from soil to seeds.

Keywords: iron, embryos, microbiota, micronutrients, plant immunity, Pseudomonas simiae WCS417, rhizosphere, seeds. 
Abbreviations: ABA: abscisic acid; AMF: Arbuscular mycorrhizal fungi; ASC: ascorbate; BGLU42 $\beta$ GLUCOSIDASE42; DMA: deoxymugeinic acid; ET: Ethylene; ETI: Effector-triggered immunity; FIT: FERlike Iron Deficiency-Induced Transcription factor; GA: Gibberellic acid; ISR: Induced systemic resistance; JA: Jasmonic acid; MAMPs: Microbe-Associated Molecular Patterns; MTI: MAMPTriggered Immunity; NA: Nicotianamine; NO: Nitric Oxide; PAMPs: Pathogen Associated Molecular Patterns; PGPR: Plant Growth-Promoting Rhizobacteria; PGPF: Plant Growth-Promoting Fungi; PRs: Pathogenesis-related (PR) Proteins; PRRs: Pattern-Recognition Receptors; PS: Phytosiderophores; PTI: PAMP-Triggered Immunity; ROS: Reactive Oxygen Species; SA Salicylic Acid; SAR: Systemic Acquired Resistance; VOC: Volatile Organic Compound; WCS417: Pseudomonas simiae WCS417. 


\section{Introduction}

Iron $(\mathrm{Fe})$ participates in fundamental processes in plants (i.e. respiration, photosynthesis, antioxidant defenses) as well as in many biochemical pathways (e.g., hormones and secondary metabolisms) and is, therefore, an essential micronutrient (Murgia et al., 2012; Kobayashi and Nishizawa, 2012; Briat et al., 2015; Connorton et al., 2017; Vigani and Murgia, 2018; Kobayashi et al., 2019). Iron can exert this role in various chemical forms, such as Fe-heme groups, Fe-S clusters or nitrosyl-Fe complexes (Ramirez et al., 2011). Nonetheless, especially when in a free non-complexed form, Fe represents a severe threat to cells due to its pro-oxidant action (Lodde et al., 2021). For these reasons, Fe uptake from the soil, its transport and distribution to various plant organs and tissues, its subcellular compartmentalization and seed loading with Fe are all utterly regulated processes, role of which is to ensure that plant cells receive enough $\mathrm{Fe}$ in the safest chemical form. Iron deficiency causes chlorosis in plants, with adverse consequences for plant health and growth, leading to yield loss (Ramirez et al., 2011; Vigani et al., 2013; Vigani and Murgia, 2018). Iron excess is also detrimental and it leads to overproduction of reactive oxygen species (ROS), damage to macromolecules, the "bronzing" symptoms, upregulation of ROS scavenging systems and downregulation of Fe uptake genes (Murgia et al., 2002; Arnaud et al., 2006; Ramirez et al., 2011; Aung and Masuda, 2020; Lodde et al., 2021). An accurate control of Fe homeostasis reduces the risk of progressive damage caused by cellular Fe excess/deficiency and it can also reduce the metabolic costs for keeping such damages under control.

Although $\mathrm{Fe}$ is abundant in soils, mostly present as ferric (hydro)oxides, its availability to plants is limited, due to an extremely low solubility of such oxides; for example, $\mathrm{Fe}(\mathrm{OH})_{3} \mathrm{~K}_{\mathrm{sp}}$ is $4 \times 10^{-38}$ (Lindsay and Schwab, 1982; Schwertmann, 1991; Colombo et al., 2014) implying that, at neutral or basic $\mathrm{pH}$, the concentration of Fe(III) is extremely low. Mechanisms of plant Fe uptake from soil have been classified as either an 'acidification-reduction strategy' (Strategy I) adopted by non-graminaceous plants, or as a 'chelation strategy' (Strategy II) adopted by Graminaceae. In Strategy I plants, soil acidification by plasma membrane $\mathrm{H}^{+}$-ATPase is followed by reduction of $\mathrm{Fe}(\mathrm{III})$ to $\mathrm{Fe}$ (II) and $\mathrm{Fe}(\mathrm{II})$ transport into epidermal root cells. Strategy II relies instead on the extrusion of phytosiderophores (PS) by TRANSPORTER OF MUGINEIC ACID (TOM) transporter; PS can chelate Fe(III) and the complex $\mathrm{Fe}$ (III)-PS is then transported into cell roots by members of the YELLOW STRIPE-LIKE (YSL) transporter family.

Such strategies are finely regulated at both transcriptional and post-transcriptional levels. As an example, the activation of $\mathrm{Fe}$ uptake in Arabidopsis thaliana plants through AHA2, FERRIC REDUCTASE OXIDASE2 (FRO2) which reduces Fe(III) to Fe(II), and IRON ROOT TRANSPORTER1 (IRT1) which transports Fe(II) into root cells, is transcriptionally regulated by the basic helix-loop-helix (bHLH) FER-LIKE IRON DEFICIENCY-INDUCED TRANSCRIPTION FACTOR (FIT) (Colangelo and Guerinot, 2004; Jakoby et al., 2004, Bauer et al., 2007). FIT activation is mediated by the ethylene-responsive transcription factors ETHYLENE INSENSITIVE3 (EIN3) and EIN3-Like1 (EIL1) (Lingam et al., 2011). Furthermore, other bHLH proteins (bHLH038, bHLH039, bHLH100 and bHLH101) interact with FIT and their expression increase under Fe deficiency (Wang et al., 2007; Wang et al., 2013). Most recently, the upstream regulatory role of bHLH121 (UPSTREAM REGULATOR of IRT1, URI) on the Fe homeostasis network has been unveiled and it involves the activation of various genes, among which FIT (Kim et al., 2019), through its interaction with bHLH105 (IRL3) (Gao et al., 2020); yeast twohybrid and chromatin immunoprecipitation (ChIP) assays, show that FIT is not a direct target of 
bHLH121 (Gao et al., 2020).

A complex regulation of $\mathrm{Fe}$ uptake occurs at post-transcriptional level. IRT1 is present in endosomes/trans-Golgi network compartments (EE/TGN) and its degradation and recycling between $\mathrm{EE} / \mathrm{TGN}$ and the plasma membrane are modulated by ubiquitination and monoubiquitin-dependent endocytosis (Barberon et al., 2011). IRT1 is ubiquitinated on the plasma membrane by the action of IRT1 DEGRADATION FACTOR1 (IDF1), a RING-type E3 ubiquitin ligase. IRT1 also mediates the transport of other metals, like Zinc ( $\mathrm{Zn}$ ), Manganese (Mn) and Cobalt (Co) which accumulate in plant tissues under Fe deficiency (Barberon et al., 2014; Vigani and Hanikenne, 2018). To limit IRT1mediated metals accumulation, IDF1 facilitates its degradation through a negative feedback loop (Barberon et al., 2014). Such a mechanism involves other proteins, namely PHOSPHATIDYLINOSITOL3-PHOSPHATE-BINDING PROTEIN FYVE1 and SORTING NEXIN SNX, required for IRT1 recycling in plants (Barberon et al., 2014; Ivanov et al., 2014). Due to such a recycling process, IRT1 is part of the metal sensing machinery (Dubeaux et al., 2018) and therefore IRT1 has been proposed to be a transceptor for metals homeostasis in plants (Cointry and Vert, 2019). Updated descriptions of both strategies and their multiple-level regulations, can be found in recent reviews (Schwarz and Bauer 2020; Gao and Dubos, 2021; Riaz and Guerinot, 2021).

The boundaries between the two Fe acquisition strategies are fading (Grillet and Schmidt, 2019); for instance, the graminaceous Oryza sativa (rice) adopts Strategy II, but it can also induce Fe transporters OsIRT1 and OsIRT2, which are hallmarks of Strategy I (Ishimaru et al., 2006; Wairich et al., 2019). The combination of both strategies, referred to as 'combined strategy' (CS), appears to be an adaptation to flooded soils, a situation implying oxygen $\mathrm{O}_{2}$ depletion and a reduction of soil potential, with a consequent increase in Fe(II) concentration (Marìnes-Cunca et al., 2015; Wairich et al., 2019). Notably, Strategy I plants can also exude various compounds with iron-mobilizing properties (Palmer et al., 2013; Zamioudis et al., 2015; Sisó-Terraza et al., 2016; Stringlis et al., 2019; Yu et al., 2021). In particular, coumarins are secondary plant metabolites synthesized by the phenylpropanoid pathway that can promote root Fe uptake. Indeed, they are secreted by roots under Fe-deficiency, through ATP-BINDING CASSETTE G37/ PLEIOTROPIC DRUG RESISTANCE 9 (ABCG37/PDR9) transporter (Fourcroy et al., 2014; Fourcroy et al., 2016; Ziegler et al., 2017) and display Fe-mobilizing, chelating and reducing properties (Schmid et al., 2014; Tsai and Schmidt, 2017; Ziegler et al., 2017; Tsai et al., 2018; Rajniak et al., 2018; Stassen et al., 2021).

The transport of the various coumarin molecules is a complex and dynamic process; Robe et al. (2021a) investigated their pattern of accumulation in the various root cell types and they also demonstrated that coumarins can be transported from roots to aerial parts through the xylem; moreover, these authors also showed evidence that various plant species (belonging to both dicotyledons and gymnosperms) can take up coumarins from the rhizosphere (Robe et al., 2021a). An updated model of such a complex picture of coumarins distribution in roots and of the transcriptional regulation of their biosynthesis, is proposed by Robe et al. (2021b), where outstanding questions regarding the biology of coumarins are also discussed; indeed, various components are still missing from the picture, such as the identities of all the glycosyltransferases and of $\beta$-glucosidases involved, as well as the direct regulators of coumarin biosynthesis genes.

A further level of the emerging complexity in Fe acquisition from the soil is represented by the microbial communities growing in the proximity of plant roots, as they can exert beneficial or 
harmful actions, favouring or inhibiting Fe uptake. Indeed, cooperation and/or competition for nutrients, including $\mathrm{Fe}$, are established among the myriad of microbes living close to roots and between plants and microorganisms, in a tripartite interaction involving plants, microorganisms and Fe. Given the emerging findings on this subject, we focus first on this "tug of war" for iron nutrition (Herlihy et al., 2020), which involves microorganisms, their colonization of plant niches and their interaction with plants. Volatile organic compounds (VOCs), emitted by plants and microorganisms, also influence the belowground interactions among plants and microorganisms and are emerging as potent regulators of these multiple interactions. VOCs-dependent microbe-plants interactions are not discussed here; readers are referred to recent publications (Zamioudis et al., 2015; Delory et al., 2016; Schulz-Bohm et al., 2017; Garbeva and Weisskopf, 2020; Gulati et al., 2020).

\section{1) Plant Fe uptake, soil and microorganisms: the plant holobiont}

Plants co-evolved with the soil microbes living in the 'rhizosphere', i.e. in the soil volume $11-3 \mathrm{~mm}$ in thickness), which is adherent to roots and influenced by roots' secretions. The rhizosphere is a remarkable reservoir of microbial biodiversity as it contains up to $10^{11}$ microorganisms per gram root (Berendsen et al., 2012; Sasse et al., 2018).

A dense and diversified array of microorganisms is thus present in the soil, which includes organisms belonging to Archaea, Bacteria and Eukarya domains, collectively named 'soil microbiota' (the collection of all their genomes is referred to as the 'microbiome') (Lynch and Pedersen, 2016; Trivedi et al., 2020; Pascale et al., 2020). The development, health and, ultimately, the phenotype of a plant is influenced by the microbial communities living in the rhizosphere and by the combined expression of both the host plant genome and its associated microbiome (Nihorimbere et al., 2011; Berendsen et al., 2012; Trivedi et al., 2020; Pascale et al., 2020). These findings led to the concept of the 'holobiont' (Vandenkoornhuyse et al., 2015; Sánchez-Cañizares et al., 2017; Simon et al., 2019). Complex plant-microorganisms and microorganisms-microorganisms interactions occur in the rhizosphere (Trivedi et al., 2020). Root exudates may shape the microbial communities living in the rhizosphere, by serving as nutrients or selective agents: the plant root microbiota are therefore different from the microbiota in the soil far away from plants, according to a phenomenon known as 'the rhizosphere effect' (Bakker et al., 2013; Bakker et al., 2020). In return, members of the plant microbiota may cause severe diseases, however they usually act as mutualists: plant growthpromoting rhizobacteria (PGPR) and plant growth-promoting fungi (PGPF) within the plant microbiota affect host nutrition, development and the immune system, by promoting plant growth or stimulating defense responses (Jogaiah and Abdelrahman, 2019; Verbon et al., 2019; Pascale et al., 2020). Beneficial root bacteria are usually a minor fraction in the rhizosphere; nonetheless, several studies have found that these bacteria may positively enhance plant yield and growth, and their pivotal role in plant life has recently been discussed (Van Loon, 2007; Ipek and Esitken, 2017; Majeed et al., 2018; Compant et al., 2019; do Amaral et al., 2020).

Pseudomonas simiae WCS417 (syn. Pseudomonas fluorescens WCS417, hereafter simply WCS417) is among the PGPR studied in the greatest detail (see BOX1 for details on plant immune responses). WCS417 can promote plant growth and induce Induced Systemic Resistance (ISR) against a wide range of diseases in A. thaliana and other plant species (Pieterse et al., 2020). WCS417 actively 
colonizes roots, suppressing the local immune responses activated by its MAMPs (Stringlis et al., 2018a) and outcompeting other microbial strains, including related sub-group members (Bakker et al., 2013; Pangesti et al., 2017). WCS417-ISR initiation in A. thaliana roots depends on plant MYB72 transcription factor (TF) and its target $\beta$-GLUCOSIDASE42 (BGLU42), which deglycosylates the coumarin scopolin (Palmer et al., 2013; Zamioudis et al., 2014; Zamioudis et al., 2015; Verbon et al., 2017; Stringlis et al., 2018b; Yu et al., 2021). MYB72 and its paralogue MYB10 regulate the Fe deficiency regulatory cascade and are functionally redundant (Palmer et al., 2013).

The phenylpropanoid pathway is often up-regulated under Fe deficiency conditions; various phenolic compounds show anti-microbial activity and can also strongly influence Fe uptake (Aznar et al., 2015). Both MYB72 and MYB10 emerged as TFs required in Fe deficient roots, to adapt to low Fe levels and to regulate the biosynthesis and release of coumarins (Palmer et al., 2013; Zamioudis et al., 2015; Stringlis et al., 2018b; Stringlis et al., 2019; Yu et al., 2021). Coumarins also emerged as important shapers of root microbiota, and they have anti-microbial potential upon pathogen infection (Voges et al., 2019; Liu et al., 2021).

MYB72 therefore has a dual function in both plant immunity and Fe homeostasis (Stringlis et al., 2018b; Stringlis et al., 2019). Indeed, WCS417 and Fe deficiency favour coumarins' secretion in a MYB72-dependent manner (Pieterse et al., 2020 and references therein). Not only, MYB72 also represents a node of convergence between the onset of ISR by beneficial microbes, such as WCS417, and Fe deficiency response; MYB72, together with MYB10, is a direct target of bHLH121 (Gao et al., 2020) and its expression is itself regulated by the TFs involved in the Fe deficiency response, i.e., FIT (bHLH029) and bHLH038, under activation of the hormone Ethylene (ET). ET could therefore represent the linking molecule between ISR and Fe deficiency response, with BGLU42 and MYB72 as nodes of convergence between ISR and Fe-deficiency (Romera et al., 2019). Notably, WCS417 can activate an Fe deficiency response in A. thaliana even when Fe levels are sufficient, with consequent improved Fe nutrition and growth (Verbon et al., 2019). For example, WCS417 is particularly tolerant to the antimicrobial activity of the coumarins scopolin and scopoletin, and it stimulates their secretion, to possibly favour its plant niche colonization in exchange for growth and immunity benefits for the plant (Verbon et al., 2019; Yu et al., 2021).

Iron-chelating compounds, the siderophores, are released not only by Strategy II graminaceous plants for Fe uptake but also by several microorganisms, in a condition of Fe deficiency (Miethke and Marahiel, 2007; Aznar et al., 2014; Aznar et al., 2015). Microbes indeed produce these lowmolecular-weight compounds with a high affinity for Fe(III) to form Fe-siderophore complexes that are internalized by the microbial cell, thus resembling the above-mentioned plant Strategy II (Herlihy et al., 2020 and references therein) and outcompeting other soil microbial strains, by making iron unavailable (Osorio Vega, 2007; Nihorimbere et al., 2011). As an example, the iron-chelating fluorescent pigment pyoverdine is produced by WCS417 (Pieterse et al., 2020). The density of the soil microbial population can also influence Fe uptake. Indeed, a dense microbial population causes a reduction in $\mathrm{O}_{2}$ concentration due to its respiratory activity, accompanied by a consequent rise in carbon dioxide $\mathrm{CO}_{2}$. Such a condition favours the conversion of Fe(III) to $\mathrm{Fe}(\mathrm{II})$ (Osorio Vega, 2007). Remarkably, WCS417 stimulates Fe deficiency responses in A. thaliana only when bacteria colonizing roots are in adequate amount, both under Fe-sufficient and Fe-deficient conditions (Verbon et al., 2019). Moreover, the WCS417-root Fe deficiency responses are regulated by a shoot-to-root signalling system unrelated to leaf Fe status, suggesting the possible involvement of novel phloem- 
mobile shoot-to-root signals and phytohormones, such as auxin (see below). Despite progress in the field, mechanisms for the induction of Fe deficiency responses by PGPR and their effect on plant Fe homeostasis are still unclear and require further investigations.

Since Fe is a limiting element in alkaline soils, it is not surprising that Fe plays a key role in the interactions between plants and non-beneficial or even pathogenic microorganisms. Fe is indeed also required by pathogens for survival: low-affinity and high-affinity strategies have been developed by phytopathogens to take up Fe from plants, and siderophores are used to sequester Fe and play a key role in microbial virulence (Franza and Expert, 2013; Aznar et al., 2015; Verbon et al., 2017; Liu et al., 2021). Many plant genes involved in Fe homeostasis are up-regulated during pathogen attack, and biotic stresses perturb plant Fe homeostasis (Aznar et al., 2015). As reported by Liu et al. (2021), plant Fe levels significantly contribute to plant protection against biotic stresses, as Fe withholding or Fe accumulation strategies might occur at the site of infection. The link between Fe homeostasis and plant immunity is quite complex: Fe homeostasis could contribute to the activation of ISR mediated by beneficial microbes (see Box 1 ). The discovery of a link between plant ISR and Fe homeostasis first occurred by the observation of a stronger induction of ISR by Pseudomonas spp against Fusarium infection in Fe deficient radish (Leeman et al., 1996). Hormones may represent interesting mediators to explore, particularly ET and nitric oxide (NO), which are both implicated in Fe deficiency responses and the activation of plant immune responses (Romera et al., 2019). ET levels may affect plant status in various ways, as its effects are influenced by the plant genotype, growth stage, plant organ and associated microbiota (Iqbal et al., 2017; Nascimento et al., 2018; Ravanbakhsh et al., 2018). ET levels are affected by plant microbiota activity, and strong relations between beneficial rhizobacteria, Fe deficiency responses and ISR activation have been recently exposed (Herlihy et al., 2020). As reviewed elsewhere in detail (Verbon et al., 2017; Romera et al., 2019), bacteria stimulating ISR could also stimulate Fe deficiency responses because of an overlap of regulatory pathways shared between the two processes, which involve several hormones such as ET, NO, auxin and the TF MYB72 (see above). Moreover, the effects of Jasmonic acid (JA) and SA on Fe nutrition as well as their roles on Fe deficiency responses have been also investigated (Kong et al., 2014; Shen et al., 2016; Boukari et al., 2019; Kabir et al., 2021). Interestingly, JA treatment increases Fe deficiency symptoms in Arabidopsis; indeed JA promotes FIT degradation by regulating the expression of various bHLH genes (Cui et al., 2018). A model describing the nodes of convergence between root Fe uptake, the rhizosphere microbiota with a highlight on WCS417, and plant immunity is presented in Figure 1.

The study of wild crops is also helpful for the elucidation of the variety of strategies activated by various plants to bypass poor soil Fe availability and the adaptation of their root apparatus together with their interaction with the rhizosphere. An example of such a field-to-lab approach was recently described in Tato et al., (2021): in this study, the plasticity and exudation of the roots of Parietaria judaica (pellitory of the wall), a wild calcicole plant growing spontaneously in an urban environment impaired in Fe availability, have been analysed; its root-associated microbiome has been also profiled. Results show that $P$. judaica roots exudate caffeoylquinic acid derivatives under calcareous conditions; they also indicate that this plant recruits beneficial soil microbes such as PGPR and phosphate solubilizers and, possibly, exclude other soil microbiota from their rhizosphere (Tato et al., 2021). 


\section{2) Fe transport from roots to stem and leaves and its distribution within}

cellsThe complexity of $\mathrm{Fe}$ homeostasis is emerging at the soil-root interface and during $\mathrm{Fe}$ distribution from roots to aboveground tissues. Contents of citrate, malate and succinate are elevated in the xylem, under Fe-deficient conditions (Lopez-Millan et al., 2010). Iron transport in the xylem to shoots predominantly occurs as Fe (III)-citrate complexes (Durrett et al., 2007; RellánÁlvarez et al., 2008; Rellán-Álvarez et al., 2010). A. thaliana FERRIC REDUCTASE DEFECTIVE3 (FRD3) and its rice ortholog FERRIC REDUCTASE DEFECTIVE LIKE1 (FRDL1) mediate the transport of citrate and iron to the xylem (Yokosho et al., 2016). Besides FRD3, FERROPORTIN1 (FPN1) is also responsible for Fe loading into the xylem, in A. thaliana plants (Morrissey et al., 2009). Once it reaches the leaves, Fe is unloaded from the apoplastic space into the cells thanks to YSL transporters, such as AtYSL1, AtYSL2, and AtYSL3 (DiDonato et al., 2004; Waters et al., 2006).

In particular, A. thaliana AtYSL2 is involved in the distribution of Fe from the xylem to shoot cells (DiDonato et al., 2004), whereas AtYSL1 and AtYSL3 are involved in the Fe-NA translocation from senescent leaves into the inflorescences and seeds and, hence, in Fe allocation throughout the phloem. Some orthologs of such YSL transporters have also been identified in rice: OsYSL2, likely involved in the Fe(II)-Nicotianamine (NA) translocation to shoots and seeds (Ishimaru et al., 2010), OsYSL16 which contributes to Fe(III)-deoxymugeinic acid (DMA) allocation via the vascular bundle (Kakei et al., 2012) and OsYSL18 which transports Fe(III)-DMA in reproductive organs and phloem of lamina joints (Aoyama et al., 2009). Additionally, the OLIGOPEPTIDE TRANSPORTER 3 (OPT3) is involved in the phloematic Fe transport and it mediates Fe shoot-to-root signalling (Mondoza-Cozal et al., 2014; Zhai et al., 2014; Khan et al., 2018).

$\mathrm{Fe}(\mathrm{III})$ is usually reduced to Fe(II), in order to cross cellular membranes (Jain et al., 2014). As already mentioned in the introduction, plants cells finely control the homeostasis of intracellular free $\mathrm{Fe}$ ions, to avoid the production of excess ROS, by transporting Fe(II) into vacuoles (Kim et al., 2006; Sharma et al., 2016) or by storing it as Fe(III) in the mineral core of the 24-mer ferritin protein cage (Briat et al., 2010; Lodde et al., 2021). A. thaliana possesses four ferritin isoforms (ATFER1-4) with plastidial and mitochondrial localization (Petit et al., 2011; Zancani et al., 2004; Tarantino et al., 2010a; Tarantino et al., 2010b). The developmental and environmental regulation of AtFer1 gene expression has been analyzed in detail, including during both natural and dark-induced senescence (Tarantino et al., 2003; Murgia et al., 2007), as well as its dependence on the nitric oxide signalling network (Murgia et al., 2002; Arnaud et al., 2006), circadian rhythm (Duc et al., 2009), phosphate homeostasis (Bournier et al., 2013) and oxidative stress (Ravet et al., 2009a; Ravet et al., 2012; Reyt et al., 2015).

In the cytoplasm, Fe likely forms complexes with organic acids and nicotianamine (NA) forming Fe(III)-citrate, Fe(III)-NA and Fe (II)-NA (von Wiren et al., 1999; Rellán-Álvarez et al., 2010; Bashir et al., 2016; Flis et al., 2016) that would be available for uptake by chloroplasts, which are the major intracellular sink of intracellular Fe; intracellular Fe homeostasis has been recently extensively reviewed in Vigani et al. (2019).

Mitochondria also represent a relevant intracellular Fe sink (Vigani et al., 2015). A Fe reductionbased strategy has been suggested to occur in plant mitochondria. FRO3 and FRO8 are involved in $\mathrm{Fe}$ (III) reduction at the mitochondrial membrane, and MITOCHONDRIAL IRON TRANSPORTERS (MIT) mediate the Fe translocation from the cytoplasm to the mitochondrial matrix (Jain and Connolly, 
2013) and the knocking down of MIT impairs plant growth and metabolism in rice (Bashir et al., 2011; Vigani et al., 2016). Accordingly, A. thaliana MIT1 and MIT2 are involved in mitochondrial Fe import and play an essential role in cellular and mitochondrial Fe homeostasis (Jain et al., 2019)

Fe deficiency-induced alteration of mitochondrial functionality impacts cellular metabolism; the characterization of the mitochondrial proteome of Fe-deficient Cucumis sativus (cucumber) roots indeed revealed a differential protein expression of mitochondrial enzymes involved in several metabolic pathways (Vigani et al., 2017). Among these enzymes, formate dehydrogenase (FDH), which catalyzes the oxidation of formate $\left(\mathrm{HCOO}^{-}\right)$into carbon dioxide $\left(\mathrm{CO}_{2}\right)$, deserves a particular mention; indeed, its abundance in cucumber roots depends on the Fe nutritional status of the plants (Vigani et al., 2017). Moreover, Nicotiana tabacum (tobacco) FDH overexpressing plants show altered Fe homeostasis as Fe content is reduced in their roots, stems and seeds (Murgia et al., 2020). A recent systems biology-oriented approach revealed that FDH might be considered a protein hub for plant nutrition (Di Silvestre et al., 2021).

Notably, the accumulation of FDH transcript has been documented under several unfavourable conditions, suggesting that FDH might be considered a stress-responsive enzyme in plants (Alekseeva et al., 2011). Most recently, evidence for FDH as part of the early response against the leaf infection by the pathogen Xanthomonas campestris pv campestris (Xcc) has been shown (Marzorati et al., 2021): the local accumulation of formate due to a decrease in FDH expression has been proposed as a possible signal for plant defense responses to pathogen's entry through the hydathodes (Marzorati et al., 2021). Taken together, these findings on FDH would strongly suggest it as a possible node of the multiple interactions between plant immune responses and $\mathrm{Fe}$ homeostasis, as proposed in Figure 2.

\section{3) Seed Fe loading: when, where and how}

Seed development consists of various morphogenetic steps that guarantee a correct development of the embryo and of its surrounding tissues, followed by seed maturation, in which coordinated changes of its three components, i.e. the embryo, the endosperm and the surrounding maternal tissues, occur. After completion of this maturation phase, a desiccation phase guarantees the seed's entrance into a quiescent state, so that it becomes able to survive in harsh environmental conditions (Gutierrez et al., 2007). The final morphological extent and physiological impact of the embryo, the endosperm and the surrounding maternal tissues on the mature seed will define the final seed architecture. Although this architecture is not fixed and it is species-specific, still all the angiosperm seeds can be broadly classified according to the prevalence of the endosperm in mature seeds (endospermic, non-endospermic and perispermic seeds) (Weber et al., 2005; Sreenivasulu and Wobus, 2013; Burrieza et al., 2014)).

Seeds maturation involves quite a dense and complex interaction of signalling networks aimed at guaranteeing the loading of seeds with all the necessary nutrients (essential elements, carbohydrates, storage proteins, oils) for germination and early stages of seedlings growth (Eggert and von Wiren, 2017). Also, a balance between concentrations of abscisic acid (ABA) favouring dormancy, and gibberellic acid (GA) favouring germination is achieved (Srivastava et al., 2021). ROS concentration in mature seeds is also of paramount importance and should fall within a specific 
range, known as the "oxidative window" and representing the ROS range enabling imbibed seeds to germinate (Gutierrez et al., 2007; Bailly et al., 2019; Lodde et al., 2021).

Species-specific plant architecture, including final seed architecture, will influence the mechanisms by which Fe is transferred from mother plant tissues into developing seeds; such mechanisms are quite complex as they involve the senescence of older plant parts with mobilization of $\mathrm{Fe}$, its transport and distribution to the developing seed. In other words, the questions of "when" $\mathrm{Fe}$ is transferred from plants to seeds, "where" Fe is compartmentalized inside maturing seeds as well as inside fully matured ones and "how" Fe is mobilized from germinating seeds are of paramount relevance. Such knowledge can indeed not only allow an in-depth understanding of the physiology of Fe-loading in seeds, but it can also actively assist the various experimental approaches (breeding, genome editing, selection of relevant traits from wild crops' relatives) for the production of Fe-dense crops, so important for human nutrition (Waters and Sankaran, 2011; Murgia et al., 2012; Murgia et al., 2013). The link between plant senescence and Fe homeostasis and its mobilization has been established by different research groups (Tarantino et al., 2003; Murgia et al., 2007; Shi et al., 2012; Mari et al., 2019; Murgia et al., 2020); in particular, the timing of the onset of senescence, regulated by NAC transcription factors, influences the final seed Fe content (Ricachenevsky et al., 2013) (see also the following section on wild crop relatives and NAM-B1). Notably, autophagy is an essential process for Fe remobilization from vegetative parts of the plants to seeds and indeed $A$. thaliana plants defective in autophagy retain more $\mathrm{Fe}$ in vegetative parts and show a reduced seed $\mathrm{Fe}$ content (Pottier et al., 2014; Pottier et al., 2019).

Iron loading into seed tissues, and in particular the roles of the NA, YSL genes and OPT3, has been thoroughly reviewed by Mari et al. (2020) to which readers are referred. Most recently, the role of a A. thaliana YABBY transcription factor INNER NO OUTER (INO) as regulator of Fe loading into developing seeds has been elucidated: INO binds indeed to the promoter of NATURAL RESISTANCE-ASSOCIATED MACROPHAGE PROTEIN1 gene (NRAMP1), thus inhibiting its expression; such INO inhibitory effect on NRAMP1 avoids accumulation of excess Fe into developing seeds, which would therefore protecting developing embryos from Fe toxicity caused by oxidative damage (Sun et al., 2021).

An important step of the seed loading with Fe is the reduction of Fe (III) into Fe(II), which is required for Fe transport into the embryos of dicots plants, such as pea and A. thaliana (Grillet et al., 2014a; Mari et al., 2020). Ascorbate (ASC) is responsible for such a reductive step (Grillet et al., 2014a) whereas no FRO2 homologs are apparently involved (Mari et al., 2020). Recently, an ASC transporter, named ATDX25, from the Multidrug And Toxic compound Extrusion (MATE) family, has been identified (Hoang et al., 2021). ATDX25 is expressed in flowers, seeds and seedlings and it acts as an ASC effluxer from vacuoles; its activity contributes to the Fe remobilization during germination (Hoang et al., 2021); to date, no evidence of ATDX25 involvement in seed Fe loading has been shown.

In a search for novel genes involved in metal uptake and transport, our research group focused on the circadian-regulated cytochrome P450 superfamily CYP82C4 gene, with expression dependent on Fe availability (Murgia et al., 2011). Later, CYP82C4 enzymatic activity was clarified, being responsible for the conversion of the fraxetin into sideretin (Ranjak et al., 2018). CYP82C4 gene expression appeared strongly correlated with genes involved in the early Fe deficiency response, but 
also with other genes not known to be involved in Fe homeostasis, at the time of publication. Among this second group of genes was At2g46750, which contains RY and IDE1-like motifs within its 1500 bp promoter region and it encodes a protein annotated as FAD-containing protein, at the time (Murgia et al., 2011). At2g46750 is currently annotated as L -GULONO-1,4-LACTONE OXIDASE 2 (GULLO2) and its expression, in roots of $A$. thaliana Fe deficient plants, is pH-dependent; its expression ratio at $\mathrm{pH} 7.0 / \mathrm{pH} 5.5$ is quite low (0.04) (Tsai and Schmidt, 2020). GULLO2 attracted our attention because it oxidizes L-gulono- 1,4 -lactone into ASC, with $\mathrm{H}_{2} \mathrm{O}_{2}$ as by-product; current knowledge is, however, that plants synthesize ASC, in vivo, solely via the D-mannose/L-galactose pathway and that the oxidation of L-gulono-1,4 $\gamma$-lactone by GULLO as the last ASC biosynthetic step, occurs in animal cells and not in plants (Smirnoff, 2018). To date, no physiological role has been assigned, in vivo, to GULLO2 (Eggers et al., 2021; Maruta et al., 2010); however, unpublished findings obtained so far in our research group, by using two independent $A$. thaliana gullo2 mutants would suggest its involvement in the reduction step of Fe(III) into Fe(II) in developing embryos (Murgia and coworkers, unpublished observations).

Much has been recently learned on Fe distributions within developing and mature seeds, thanks to the established Fe Perls staining technique amplified with $\mathrm{DAB} / \mathrm{H}_{2} \mathrm{O}_{2}$ stain (Roschzttardtz et al., 2009; Brumbarova and Ivanov, 2014), but also thanks to the mapping of elemental distribution in embryos and seeds by micro X-ray fluorescence ( $\mu \mathrm{XRF}$ ) or by Energy Dispersive X-ray Spectroscopy (EDS), in which radiation is provided by an electron beam (Lott and West, 2001; Takahashi et al., 2009; Fittschen et al., 2017; Cardoso et al., 2018). The model plant $A$. thaliana has been one of the first species for which the seeds have been analysed by $\mu \mathrm{XRF}$; seed analysis of wt and vit1 mutants showed that Fe accumulates in the proximity of the provasculature (Kim et al., 2006). Further studies demonstrated that $\mathrm{Fe}$ is localized in the vacuoles of the endodermal cells surrounding the provascular cambium of $A$. thaliana mature seeds (Roschzttardtz et al., 2009; Grillet et al., 2014b). Analysis of Fe distribution in maturing seeds of other Brassicaceae species, i.e., Brassica napus, Nasturtium officinale, Lepidium sativum, Camelina sativa, and Brassica oleracea, revealed that Fe is localized in the nuclei of integument, endosperm and embryo cells and that it gradually moves to surrounding structures around the nucleus to be finally loaded into vacuoles of endodermal cells surrounding the provasculature (Ibeas et al., 2017). However, Fe distribution in Vasconcellea pubescens (mountain papaya), also in the Brassicales order, showed that seed $\mathrm{Fe}$ is also retrieved in cortex cells (Ibeas et al., 2019). To establish whether the pattern of Fe localization in V. pubescens is an exception in Brassicales or rather an indication of a wider pattern than that restricted to vacuoles of endodermal cells, more species of Eudicots belonging to orders other than Brassicales were investigated; such analyses suggested that Fe distribution has indeed a wide pattern of distribution and it can even be species- and genotype-dependent (Cvitanich et al., 2010; Grillet et al., 2014b; Ibeas et al., 2019). However, another study highlighted how, among the Rosids, seed Fe is detected primarily in the endodermal cell layer of the embryo (Eroglu et al., 2019). In monocots, $\mathrm{Fe}$ is predominantly in the scutellum, aleurone layer (Ozturk et al., 2009; Lemmens et al., 2018).Fe can also be stored in ferritin within amyloplasts, in seeds of some Phaseolus species (Cvitanich et al., 2010; Grillet et al., 2014b; Moore et al., 2018). These observations are important, as legume seeds have high iron content, compared to species/families such as those of $A$. thaliana itself (Murgia et al, 2012). During the maturation stage, seeds are loaded, besides micro and macroelements, with reserve proteins, carbohydrates and triglycerides, the proportion of which strongly depends on the species; the signalling pathways for protein and oil loading involve master regulators such as LEAFY 
COTYLEDON1 (LEC1), LEC2, FUSCA3 (FUS3), ABSCISIC ACID INSENSITIVE3 (ABI3); on the other side, the lack of transcription factors orchestrating micronutrient loading, including $\mathrm{Fe}$, is puzzling (Roschzttardtz et al., 2020). In fact, Sun et al. (2020) proposed a role for ET in seed Fe loading through the signalling cascade involving its master transcriptional regulator EIN3 acting on the transcription factor ERF95, which in turn would bind to the GCC-boxes of the AtFer1 promoter; however, ATFER2 is the only ferritin protein isoform detected so far in A.thaliana seeds, whereas ATFER1 has never been detected in A.thaliana seeds (Ravet et al., 2009a; Ravet et al., 2009b; Briat et al., 2010).Hence, the proposed signalling cascade ethylene-EIN3-ERF95-FER1 (Sun et al., 2020) requires further experimental investigation.

Loading of Fe into the vacuole by the VIT1 transporter, during seed maturation, as well as its mobilization from the vacuole by NRAMP3 and NRAMP4 transporters, during germination, are important steps in the post-germinative phase; A. thaliana mutants vit1 or nramp3nramp4, compromised in these two key Fe transport steps, indeed show severe chlorosis and growth arrest, under Fe deficiency (Lanquar et al., 2005; Kim et al., 2006; Bastow et al., 2018). Rice transporters OsVIT1 and OsVIT2 share, with A. thaliana, their role of Fe transport into the vacuole: notably, osvit 1 and osvit 2 mutants accumulate more $\mathrm{Fe}$ in seeds than the corresponding wt, whereas in the same mutants a reduction of Fe content is observed in flag leaves, thus confirming that VIT transporters regulate Fe trafficking between leaves and seeds (Zhang et al., 2012). Unfortunately, osvit1 and osvit2 also accumulate the toxic heavy metal cadmium Cd(II) when grown in contaminated paddy soils (Zhang et al., 2012), thus preventing direct use of vit1 vit2 mutations for Fe biofortification approaches.

\section{4) Wild crops relatives in the amelioration of seed Fe loading}

The domestication of wild plant species, implying anatomical, morphological and genetic changes due to cultivation and selection in an anthropic environment (Charmet, 2011; Pigna and Morandini, 2017), started independently in various regions around the world between 10000 and 2000 years b.C. Domestication of wheat, which occurred in the Fertile Crescent, caused a reduction of Fe content, in both average value and variability; wild wheat, such as Triticum boeoticum, Triticum urartu, and Triticum dicoccoides (wild emmer), as well as primitive wheat T. monococcum, show a higher Fe content in grains in comparison with modern cultivars of Triticum durum (durum wheat) and Triticum estivum (bread wheat) (Cakmak et al., 2000; Cakmak et al., 2004); in particular, wheat ancestor Triticum dicoccoides has a higher Fe content, compared to cultivated Triticum aestivum and durum (Cakmak et al., 2000; Cakmak et al., 2004). Indeed, 825 wild emmer accessions all originating from different regions of the Fertile Crescent regions were tested for Fe content, as well as for zinc $(\mathrm{Zn})$, phosphorus $(\mathrm{P})$, magnesium $(\mathrm{Mg})$ and sulphur $(\mathrm{S})$, and they showed an average Fe content of 46 $\mu \mathrm{g} \mathrm{g}^{-1}$ with concentrations ranging from 15 to $109 \mu \mathrm{g} \mathrm{g}^{-1}$. Interestingly, these lines also showed higher Zn content but no difference in the other tested nutrients (Cakmak et al., 2004; Peng et al., 2007).

An interesting study took advantage of the archived samples from the Broadbalk Experiment, known as the "oldest continuous agricultural experiment in the world", to investigate mineral content in the Triticum aestivum varieties cultivated in the last 160 years, starting from 1845 (Fan et al., 2008): Zn, 
Fe, copper (Cu) and Mg contents remained stable until 1960, when short-straw cultivars were introduced. Since that introduction, a stable decline of mineral contents was observed, accompanied by an increase in seeds yield and harvest index, which are significant factors for the observed reduction in seeds' mineral content. Authors indeed suggest that mineral nutrition of the plants, among which Fe itself, would not catch-up with the improved redistribution of photosynthates in the short-straw cultivars (Fan et al., 2008). In another remarkable study, the Fe content archaeological maize kernels collected in Tarakapà Region (Atacama Desert, South America) and spanning 2000 years (according to radiocarbon dating) was analysed; obtained results show a decline in Fe content associated with the shift from ancient to more recent maize varieties.

Wild crops relatives can represent a still poorly explored reservoir of genes potentially useful for the improvement of various traits, among which are the elemental content of seeds (Charmet, 2011), including Fe itself. An illuminating example of the genetic potential of wild crops relatives is represented by the single genetic locus Gpc-B1 with Mendelian segregation and associated with a higher protein, $\mathrm{Zn}$ and Fe content; the Recombinant Chromosome Substitution Lines (RSLs) carrying the $T$. dicoccoides Gpc-B1 allele indeed showed a 18\% higher Fe concentration, when compared with lines carrying the alternative durum allele (Distelfeld et al., 2007). Thanks to map-based cloning, the gene coding for a such locus has been identified and it encodes an NAC-transcription factor named NAB-B1 (Uauy et al., 2006). Interestingly, the wt allele accelerates senescence and favours Fe and Zn mobilization from flag leaves into developing seeds (Uauy et al., 2006; Lundström et al., 2017). Intriguingly, the reduction in NAM-B1 transcript by RNA interference causes a delayed senescence. Such a trait is, however, not associated with larger seeds, suggesting that the observed reduced Fe and $\mathrm{Zn}$ concentration in plants with reduced NAM-B1 activity is not simply due to a dilution effect in seeds, but on the inefficient remobilization of these nutrients from leaf to seeds, as the higher Fe and $\mathrm{Zn}$ concentrations in NAM-B1 RNA1 flag leaves demonstrate (Uauy et al., 2006). According to Uauy and coworkers, wt NAM-B1 allele is present in all wild emmer accessions tested, and in the largest part of domesticated emmer accessions (Triticum dicoccum) whereas both the tested $T$. durum and $T$. aestivum lines lack the functional allele, as they either carry an allele with a 1-bp insertion (causing a frame shift) or a gene deletion (Uauy et al., 2006). In fact, some Swedish spring wheat varieties were demonstrated to carry the wt NAM-B1 allele, without showing any relevant difference in $\mathrm{Zn}$ and Fe content with respect to varieties carrying the null allele (Asplund et al., 2013; Lundström et al., 2017). This poses the question of the possible effect of NAM-B1 allele and of its non-functional allele, in different genetic backgrounds (Asplund et al., 2013). Also, the frequency of NAM-B1 allele in domesticated emmer wheat poses the question of whether the NAM-B1 gene can be considered a genuine domestication gene or, instead, a diversification gene (Lundström et al., 2017). Nonetheless, a years-long analysis of the NAM-B1 wt allele and its distribution among wheats, confirms that wild crops relatives represent a large and still unexplored reservoir of potentially valuable genes that can be exploited for neo-domestication approaches (Charmet, 2011; Peng et al., 2013). The annual wild species Cicer judaicum is, for example, the most promising wild crop relative for improvement of Fe content in chickpeas (Sharma et al., 2020).

The analysis of the wild progenitor of $O$. sativa, i.e. O. rufipogon, allowed to ascertain that the Combined Strategy (CS) of Fe uptake preceded rice domestication (Wairich et al., 2019). Again, these findings support the possible use of wild rice in the improvement of CS strategy, as far as seed Fe loading is concerned. 


\section{Conclusions}

The potential of beneficial rhizobacteria to activate both plant ISR defense responses and Fe uptake responses opens the possibility of using such microbial strains as biopesticides and Fe biofertilizers. Nonetheless, further studies are required to investigate the link between ISR and Fe uptake response, especially in crops under field conditions, and the various middle/long-term ecological implications that the use of such beneficial microbial strains would imply. Such studies will certainly be important for the detailed understanding of plant Fe nutrition in the field, where plants are continuously exposed to various biotic and abiotic stresses; they can also potentially impact the costs associated with reduced crop yields in alkaline soils. Thus, research on plant beneficial microorganisms and Fe nutrition appears as a very engaging field for future researchers.

The road of Fe from soil to seeds is long indeed, and it still features several question marks, one of which will be to define the precise biochemical network of transcription factors, enzymes, transporters and biochemical steps involved in moving Fe into the various seed tissues during their development and maturation. In this respect, the exploitation of genetic resources derived from Fedense seeds of wild crops' relatives, appears an attractive avenue to be explored in the short term.

\section{Acknowledgements}

The figures presented in this work were designed by using BioRender (https://biorender.com).

This work is dedicated to the memory of Delia Tarantino, who passed away two years ago at a too young age; her kindness, friendship, enthusiasm and dedication to science, are vivid in our memories and inspired our work.

\section{Authors contribution statement}

IM: Conceptualization, writing - Original Draft Preparation.

FM, GV, PM: Contributions to original draft preparation

FM: Figures preparation, with contributions of IM, GV, PM. 


\section{References}

Alekseeva AA, Savin SS, Tishkov VI. 2011. NAD+-dependent formate dehydrogenase from plants, Acta Naturae 3, 38-54. https://doi.org/10.32607/20758251- 2011-3-4-38-54.

Aoyama T, Kobayashi T, Takahashi M, Nagasaka S, Usuda K, Kakei Y, Ishimaru Y, Nakanishi H, Mori S, Nishizawa NK. 2009. OsYSL18 is a rice iron(III)-deoxymugineic acid transporter specifically expressed in reproductive organs and phloem of lamina joints. Plant Molecular Biology 70, 681-692.

Arnaud N, Murgia I, Boucherez J, Briat JF, Cellier F, Gaymard F. 2006. An iron-induced nitric oxide burst precedes ubiquitin-dependent protein degradation for Arabidopsis AtFer1 ferritin gene expression. Journal of Biological Chemistry 281, 23579-23588.

Asplund L, Bergkvist G, Leino MW, Westerbergh A, Weih M. 2013. Swedish spring wheat varieties with the rare high grain protein allele of NAM-B1 differ in leaf senescence and grain mineral content. PLoS One 8(3):e59704.

Aung MS, Masuda H. 2020. How does rice defend against excess iron? Physiological and molecular mechanisms. Frontiers in Plant Science 11:1102. doi: 10.3389/fpls.2020.0110.

Aznar A, Chen NWG, Rigault M, et al. 2014. Scavenging iron: a novel mechanism of plant immunity activation by microbial siderophores. Plant Physiology 164, 2167-2183.

Aznar A, Chen NWG, Thomine S, Dellagi A. 2015. Immunity to plant pathogens and iron homeostasis. Plant Science 240, 90-97.

Bailly C. 2019. The signalling role of ROS in the regulation of seed germination and dormancy. Biochemical Journal 476, 3019-3032. doi: https://doi.org/10.1042/BCJ20190159.

Bakker PAHM, Berendsen RL, Doornbos RF, Wintermans PCA, Pieterse CMJ. 2013. The rhizosphere revisited: root microbiomics. Frontiers in Plant Science 4, 1-7. 
Bakker PAHM, Berendsen RL, Van Pelt JA, et al. 2020. The Soil-borne identity and microbiome-assisted agriculture: looking back to the future. Molecular Plant 13, 1394-1401.

Barberon M, Zelazny E, Robert S, Conéjéro G, Curie C, Friml J, Vert, G. 2011.Monoubiquitin-dependent endocytosis of the IRON-REGULATED TRANSPORTER 1 (IRT1) transporter controls iron uptake in plants. Proceedings of the National Academy of Sciences USA, 108, E450-E458.

Barberon M, Dubeaux G, Kolb C, Isono E, Zelazny E, Vert G. 2014. Polarization of IRON-REGULATED TRANSPORTER 1 (IRT1) to the plant-soil interface plays crucial role in metal homeostasis. Proceedings of the National Academy of Sciences USA 111, 8293-8298.

Bashir K, Ishimaru Y, Shimo, H, Nagasaka S, Fujimoto M, Takanashi H, Tsutsumi N, An G, Nakanishi H, Nishizawa NK. 2011. The rice mitochondrial iron transporter is essential for plant growth. Nature Communications 2, 322.

Bashir K, Rasheed S, Kobayashi T, Seki M, Nishizawa NK. 2016. Regulating subcellular metal homeostasis: the key to crop improvement. Frontiers in Plant Science 7: 1192.

Bastow EL, Garcia de la Torre VS, Maclean AE, Green RT, Merlot S, Thomine S, Balk J. 2018. Vacuolar iron stores gated by NRAMP3 and NRAMP4 are the primary source of iron in germinating seeds. Plant Physiology 177,1267-1276. doi: 10.1104/pp.18.00478.

Bauer P, Ling HQ, Guerinot ML. 2007. FIT, the FER-LIKE IRON DEFICIENCY INDUCED TRANSCRIPTION FACTOR in Arabidopsis. Plant Physiology and Biochemistry 45, 260-261.

Berendsen RL, Pieterse CMJ, Bakker PAHM. 2012. The rhizosphere microbiome and plant health. Trends in Plant Science 17, 478-486.

Boukari N, Jelali N, Renaud JB, Youssef R Ben, Abdelly C, Hannoufa A. 2019. Salicylic acid seed priming improves tolerance to salinity, iron deficiency and their combined effect in two ecotypes of Alfalfa. Environmental and Experimental Botany 167. doi.org/10.1016/j.envexpbot.2019.103820. 
Bournier M, Tissot N, Mari S, Boucherez J, Lacombe E, Briat JF, Gaymard, F. 2013. Arabidopsis ferritin 1 (AtFer1) gene regulation by the phosphate starvation response 1 (AtPHR1) transcription factor reveals a direct molecular link between iron and phosphate homeostasis. The Journal of Biological Chemistry 288, 22670-22680. https://doi.org/10.1074/jbc.M113.482281

Briat JF, Duc C, Ravet K, Gaymard F. 2010. Ferritins and iron storage in plants. Biochimica and Biophysica Acta $1800,806-814$.

Briat JF, Dubos C, Gaymard F. 2015. Iron nutrition, biomass production, and plant product quality. Trends in Plant Science 20, 33-40.

Brumbarova T, Ivanov R. 2014. Perls staining for histochemical detection of iron in plant samples. Bioprotocol 4(18): e1245. DOI: 10.21769/BioProtoc.1245.

Burrieza HP, López-Fernández MP, Maldonado S. 2014. Analogous reserve distribution and tissue characteristics in quinoa and grass seeds suggest convergent evolution. Frontiers in Plant Science 5: 546.

Cakmak I, Ozkan H, BraunHJ, Welch RM, Romheld V. 2000. Zinc and iron concentrations in seeds of wild, primitive, and modern wheats. Food and Nutrition Bulletin, vol. 21, no. 4, 401-403.

Cakmak I, Torun A, Millet E, Feldman M, Fahima T, Korol A, Nevo E, Braun HJ, Özkan H. 2004. Triticum dicoccoides: an important genetic resource for increasing zinc and iron concentration in modern cultivated wheat. Soil Science and Plant Nutrition 50,1047-1054. DOI: 10.1080/00380768.2004.10408573

Cardoso P, Mateus TC, Velu G, Singh RP, Santos JP, Carvalho ML, Lourenço VM, Lidon F, Reboredo F, Guerra M. 2018. Localization and distribution of $\mathrm{Zn}$ and Fe in grains of biofortified bread wheat lines through micro- and triaxial-X-ray fluorescence spectrometry. Spectrochimica Acta 141, 70-79.

Charmet G. 2011. Wheat domestication: lessons for the future. Comptes Rendus Biologies 334, 212-220. doi: 10.1016/j.crvi.2010.12.013

Choi HW, Klessig DF. 2016. DAMPs, MAMPs, and NAMPs in plant innate immunity. BMC Plant Biology 16, 232. https://doi.org/10.1186/s12870-016-0921-2. 
Cointry V, Vert G. 2019. The bifunctional transporter-receptor IRT1 at the heart of metal sensing and signalling. New Phytologist 223, 1173-1178. https://doi.org/10.1111/nph.15826.

Colangelo EP, Guerinot ML. 2004. The essential basic Helix-Loop-Helix protein FIT1 is required for the iron deficiency response. Plant Cell 16, 3400-3412.

Colombo C, Palumbo G, He, JZ, Pinton R, Cesco S. 2014. Review on iron availability in soil: interaction of Fe minerals, plants, and microbes. Journal of Soils and Sediments 14, 538-548. https://doi.org/10.1007.

Compant S, Samad A, Faist H, Sessitsch A. 2019. A review on the plant microbiome: ecology, functions, and emerging trends in microbial application. Journal of Advanced Research 19, 29-37.

Connorton JM, Balk J, Rodríguez-Celma J. 2017. Iron homeostasis in plants - a brief overview. Metallomics 9, 813-823. doi:10.1039/c7mt00136c.

Conrath U, Beckers GJM, Langenbach CJG, Jaskiewicz MR. 2015. Priming for enhanced defense. Annual Review of Phytopathology 53, 97-119.

Cui H, Tsuda K, Parker JE. 2015. Effector-triggered immunity: from pathogen perception to robust defense. Annual Review of Plant Biology 66, 487-511.

Cui Y, Chen CL, Cui M, Zhou WJ, Wu HL, Ling HQ. 2018. Four IVa bHLH transcription factors are novel interactors of FIT and mediate JA inhibition of iron uptake in Arabidopsis. Molecular Plant 11, 1166-1183. https://doi.org/10.1016/j.molp.2018.06.005.

Cvitanich C, Przybyłowicz W, Urbanski D, Jurkiewicz A, Mesjasz-Przybyłowicz J, Blair M, Astudillo C, Jensen E $\varnothing$, Stougaard J. 2010. Iron and ferritin accumulate in separate cellular locations in Phaseolus seeds. BMC Plant Biology 10:26. doi: 10.1186/1471-2229-10-26.

De Lorenzo G, Ferrari S, Cervone F, Okun E. 2018. Extracellular DAMPs in plants and mammals: immunity, tissue damage and repair. Trends in Immunology 39, 937-950. https://doi.org/10.1016/j.it.2018.09.006. 
Delory BM, Delaplace P, Fauconnier ML, du Jardin P. 2016. Root-emitted volatile organic compounds: can they mediate belowground plant-plant interactions? Plant and Soil 402, 1-26.

DiDonato RJ, Roberts LA, Sanderson T, Eisley RB, Walker EL. 2004. Arabidopsis Yellow Stripe-Like2 (YSL2): a metal-regulated gene encoding a plasma membrane transporter of nicotianamine-metal complexes. The Plant Journal 39, 403-414.

Di Silvestre D, Vigani G, Mauri P, Hammadi S, Morandini P, Murgia I. 2021. Network topological analysis for the identification of novel hubs in plant nutrition. Frontiers in Plant Science 10;12:629013. doi: 10.3389/fpls.2021.629013.

Distelfeld A, Cakmak I, Peleg Z, Ozturk L, Yazici AM, Budak, H, Saranga Y, Fahima T. 2007. Multiple QTLeffects of wheat Gpc-B1 locus on grain protein and micronutrient concentrations. Physiologia Plantarum $129,635-643$.

do Amaral FP, Tuleski TR, Pankievicz VCS, et al. 2020. Diverse bacterial genes modulate plant root association by beneficial bacteria. ASM Journals mBio 11, 1-15.

Dubeaux G, Neveu J, Zelazny E, Vert G. 2018. Metal sensing by the IRT1 transporter-receptor orchestrates its own degradation and plant metal nutrition. Molecular Cell 69, 953- 964. e955.

Duc C, Cellier F, Lobréaux S, Briat JF, Gaymard F. 2009. Regulation of iron homeostasis in Arabidopsis thaliana by the Clock Regulator Time for Coffee. Journal of Biological Chemistry 284, 36271-36281. https://doi.org/10.1074/jbc.M109.059873.

Durrett TP, Gassmann W, Rogers EE. 2007. The FRD3-mediated efflux of citrate into the root vasculature is necessary for efficient iron translocation. Plant Physiology 144, 197-205.

Eggers R, Jammer A, Jha S, Kerschbaumer B, Lahham M, Strandback E, Toplak M, Wallner S, Winkler A, Macheroux P. 2021. The scope of flavin-dependent reactions and processes in the model plant Arabidopsis thaliana. Phytochemistry 189, 112822. https://doi.org/10.1016/j.phytochem.2021.112822.

Eggert K, von Wiren N. 2017. Dynamics and partitioning of the ionome in seeds and germinating seedlings of winter oilseed rape. Metallomics 5, 1316-1325. 
Elgueta AV, Navarro N, Uribe M, Robe K, Gaymard F, Dubos C, Pérez MF, Roschzttardtz H. 2021. 2000 years of agriculture in the Atacama desert lead to changes in the distribution and concentration of iron in maize. Science Reports 11, 17322. https://doi.org/10.1038/s41598-021-96819-1

Eroglu S, Karaca N, Vogel-Mikus K, Kavčič A, Filiz E and Tanyolac B. 2019. The Conservation of VIT1Dependent Iron Distribution in Seeds. Frontiers in Plant Science 10:907. doi: 10.3389/fpls.2019.00907

Fan MS, Zhao FJ, Fairweather-Tait SJ, Poulton PR, Dunham SJ, McGrath SP. 2008. Evidence of decreasing mineral density in wheat grain over the last 160 years. Journal of Trace Elements in Medicine and Biology 22, 315-24. doi: 10.1016/j.jtemb.2008.07.002.

Fittschen UEA, Kunz HH, Höhner R, Tyssebotn IMB, Fittschen A. 2017. A new micro X-ray fluorescence spectrometer for in vivo elemental analysis in plants. X-Ray Spectrometry 46, 374-381.

Flis P, Ouerdane L, Grillet L, Curie C, Mari S, Lobinski R. 2016. Inventory of metal complexes circulating in plant fluids: a reliable method based on HPLC coupled with dual elemental and high-resolution molecular mass spectrometric detection. New Phytologist 211, 1129-1141.

Fourcroy P, Sisó-Terraza P, Sudre D, Savirón M, Reyt G, Gaymard F, Abadía A, Abadia J, Álvarez-Fernández A, Briat JF. 2014. Involvement of the ABCG37 transporter in secretion of scopoletin and derivatives by Arabidopsis roots in response to iron deficiency. New Phytologist 201,155-167. doi: 10.1111/nph.12471.

Fourcroy P, Tissot N, Gaymard F, Briat JF, Dubos C. 2016. Facilitated Fe nutrition by phenolic compounds excreted by the Arabidopsis ABCG37/PDR9 transporter requires the IRT1/FRO2 high-affinity root Fe2+ transport system. Molecular Plant 9, 485-488. https://doi.org/10.1016/j.molp.2015.09.010.

Franza T, Expert D. 2013. Role of iron homeostasis in the virulence of phytopathogenic bacteria: An 'à la carte' menu. Molecular Plant Pathology 14, 429-438.

Fu ZQ, Dong X. 2013. Systemic acquired resistance: turning local infection into global defense. Annual Review of Plant Biology 64, 839-863. 
Gao F, Robe K, Bettembourg M, Navarro N, Rofidal V, Santoni V, Gaymard F, Vignols F, Roschzttardtz H, Izquierdo E, Dubos C. 2020. The transcription factor BHLH121 interacts with BHLH105 (IRL3) and its closest homologs to regulate iron homeostasis in Arabidopsis. Plant Cell 32, 508-524. doi: 10.1105/tpc.19.00541.

Gao F, Dubos C. 2021.Transcriptional integration of plant responses to iron availability. Journal of Experimental Botany 72, 2056-2070. doi: 10.1093/jxb/eraa556.

Garbeva P, Weisskopf L. 2020. Airborn medicine: bacterial volatiles and their influence on plant health. New Phytologist 226, 32-43. doi: 10.1111/nph.16282.

Grillet L, Ouerdane L, Flis $\mathbf{P}$, Hoang $\mathbf{M}$, Isaure $\mathbf{M}$, Lobinski R, Curie C, Mari S. 2014a. Ascorbate efflux as a new strategy for iron reduction and transport in plants. Journal of Biological Chemistry 289, 2515-2525. doi: 10.1074/jbc.M113.514828.

Grillet L, Mari S, Schmidt W. 2014b. Iron in seeds - loading pathways and subcellular localization. Frontiers in Plant Science 4:535. doi: 10.3389/fpls.2013.00535.

Grillet L, Schmidt W. 2019. Iron acquisition strategies in land plants: not so different after all. New Phytologist 224, 11-18

Gulati S, Ballhausen MB, Kulkarni P, Grosch R, Garbeva P. 2020. A non-invasive soil-based setup to study tomato root volatiles released by healthy and infected roots. Scientific Reports 10, 12704. https://doi.org/10.1038/s41598-020-69468-z.

Gutierrez L, Van Wuytswinkel O, Castelain M, Bellini C. 2007. Combined networks regulating seed maturation. Trends in Plant Science 12, 294-300.

Herlihy JH, Long TA, McDowell JM. 2020. Iron homeostasis and plant immune responses: recent insights and translational implications. Journal of Biological Chemistry 295, 13444-13457.

Hoang MTT, Almeida D, Chay S, Alcon C, Corratge-Faillie C, Curie C, Mari S. 2021. AtDTX25, a member of the multidrug and toxic compound extrusion family, is a vacuolar ascorbate transporter that controls intracellular iron cycling in Arabidopsis. New Phytologist 231,1956-1967. doi: 10.1111/nph.17526. 
Ibeas MA, Grant-Grant S, Navarro N, Perez MF, Roschzttardtz H. 2017. Dynamic subcellular localization of iron during embryo development in Brassicaceae seeds. Frontiers in Plant Science 8:2186. doi: 10.3389/fpls.2017.02186.

Ibeas MA, Grant-Grant S, Coronas MF. et al. 2019. The diverse iron distribution in Eudicotyledoneae seeds: from Arabidopsis to Quinoa. Frontiers in Plant Science 9:1985. doi: 10.3389/fpls.2018.01985.

Ipek M, Esitken A. 2017. The actions of PGPR on micronutrient availability in soil under calcareous soil conditions: an evaluation over Fe nutrition. In: Singh D., Singh H., Prabha R. (eds) Plant-Microbe Interactions in Agro-Ecological Perspectives. Springer, Singapore. https://doi.org/10.1007/978-981-106593-4_4.

Iqbal N, Khan NA, Ferrante A, Trivellini A, Francini A, Khan MIR. 2017. Ethylene role in plant growth, development and senescence: interaction with other phytohormones. Frontiers in Plant Science 8, 1-19.

Ishimaru Y, Suzuki M, Tsukamoto T. et al. 2006. Rice plants take up iron as an $\mathrm{Fe}^{3+}$-phytosiderophore and as $\mathrm{Fe}^{2+}$. The Plant Journal 45, 335-346

Ivanov R, Brumbarova T, Blum A, Jantke AM, Fink-Straube C. and Bauer, P. 2014. SORTING NEXIN1 is required for modulating the trafficking and stability of the Arabidopsis IRON-REGULATED TRANSPORTER1. Plant Cell 26, 1294-1307. doi: 10.1105/tpc.113.116244

Ishimaru Y, Masuda H, Bashir K. et al. 2010. Rice metal-nicotianamine transporter, OsYSL2, is required for the long-distance transport of iron and manganese. The Plant Journal 62, 379-390.

Jain A, Connolly EL. 2013. Mitochondrial iron transport and homeostasis in plants. Frontiers in Plant Science 4, 348. https://doi.org/10.3389/fpls.2013.00348

Jain A, Wilson GT, Connolly EL. 2014. The diverse roles of FRO family metalloreductases in iron and copper homeostasis. Frontiers in Plant Science 5, 100. doi: 10.3389/fpls.2014.00100.

Jain A, Dashner ZS, Connolly EL. 2019. Mitochondrial Iron Transporters (MIT1 and MIT2) are essential for iron homeostasis and embryogenesis in Arabidopsis thaliana. Frontiers in Plant Science 10:1449. doi: 10.3389/fpls.2019.01449. 
Jogaiah S, Abdelrahman M. 2019. Bioactive Molecules in Plant Defense. Signaling in Growth and Stress. Springer Eds, 1-248.

Jakoby M, Wang HY, Reidt W, Weisshaar B, Bauer P. 2004. FRU (BHLH029) is required for induction of iron mobilization genes in Arabidopsis thaliana. FEBS Letters 577, 528-534.

Kabir AH, Tahura S, Elseehy MM, El-Shehawi AM. 2021. Molecular characterization of Fe-acquisition genes causing decreased Fe uptake and photosynthetic inefficiency in Fe-deficient sunflower. Scientific Reports $11,1-13$.

Kakei Y, Ishimaru Y, Kobayashi T, Yamakawa T, Nakanishi H, Nishizawa NK. 2012. OsYSL16 plays a role in the allocation of iron. Plant Molecular Biology 79, 583-594.

Khan MA, Castro-Guerrero NA, McInturf SA, Nguyen NT, Dame AN, Wang J, Bindbeutel RK, Joshi T, Jurisson SS, Nusinow DA, Mendoza-Cozat DG. 2018. Changes in iron availability in Arabidopsis are rapidly sensed in the leaf vasculature and impaired sensing leads to opposite transcriptional programs in leaves and roots Plant Cell Environment 41, 2263-2276.

Kim SA, Punshon T, Lanzirotti A, Li L, Alonso JM, Ecker JR, Kaplan J, Guerinot ML. 2006. Localization of iron in Arabidopsis seed requires the vacuolar membrane transporter VIT1. Science 314, 1295-1298.

Kim SA, LaCroix IS, Gerber SA, Guerinot ML. 2019. The iron deficiency response in Arabidopsis thaliana requires the phosphorylated transcription factor URI. Proceedings of the National Academy of Sciences 116, 24933-24942; DOI: 10.1073/pnas.1916892116.

Klessig DF, Choi HW, Dempsey DA. 2018. Systemic Acquired Resistance and Salicylic Acid: past, present, and future. Molecular Plant Microbe Interactions 31, 871-888. doi: 10.1094/MPMI-03-18-0067-CR.

Kobayashi T, Nishizawa NK. 2012. Iron uptake, translocation, and regulation in higher plants. Annual Review of Plant Biology 63, 131-152.

Kobayashi T, Nozoye T, Nishizawa, NK. 2019. Iron transport and its regulation in plants. Free Radical Biology and Medicine. 133, 11-20. 
Kong J, Dong Y, Xu L, Liu S, Bai X. 2014. Effects of foliar application of salicylic acid and nitric oxide in alleviating iron deficiency induced chlorosis of Arachis hypogaea L. Botanical Studies 55, 9. doi: 10.1186/1999-3110-55-9.

Lanquar V, Lelièvre F, Bolte S. et al. 2005. Mobilization of vacuolar iron by AtNRAMP3 and AtNRAMP4 is essential for seed germination on low iron. EMBO Journal 24, 4041-4051. doi: 10.1038/sj.emboj.7600864.

Leeman M, Den Ouden FM, Van Pelt JA, Dirkx FPM, Steijl H, Bakker PAHM, Schippers B. 1996. Iron availability affects induction of systemic resistance to Fusarium wilt of radish by Pseudomonas fluorescens. Phytopathology 86, 149-155.

Lemmens E, De Brier N, Spiers KM, Ryan C, Garrevoet J, Falkenberg G, Goos P, Smolders E, Delcour JA. 2018. The impact of steeping, germination and hydrothermal processing of wheat (Triticum aestivum L.) grains on phytate hydrolysis and the distribution, speciation and bio-accessibility of iron and zinc elements. Food Chemistry 264, 367-376.

Lindsay WL, Schwab AP. 1982. The chemistry of iron in soils and its availability to plants. Journal of Plant Nutrition 5,821-840.

Lingam S, Mohrbacher J, Brumbarova T, Potuschak T, Fink-Straube C, Blondet E, Genschik P, Bauer P. 2011. Interaction between the bHLH transcription factor FIT and ETHYLENE INSENSITIVE3/ETHYLENE INSENSITIVE3-LIKE1 reveals molecular linkage between the regulation of iron acquisition and ethylene signaling in Arabidopsis. Plant Cell 23, 1815-1829.

Liu Y, Kong D, Wu H-L, Ling H-Q. 2021. Iron in plant-pathogen interactions. Journal of Experimental Botany $72,2114-2124$.

Lodde V, Morandini P, Costa A, Murgia I, Ezquer, I. 2021. cROStalk for Life: uncovering ROS signaling in plants and animal systems, from gametogenesis to early embryonic development. Genes 12, 525. https://doi.org/10.3390/genes12040525 
López-Millán AF, Morales F, Abadía A, Abadía J. 2000. Changes induced by Fe deficiency and Fe resupply in the organic acid metabolism of sugar beet (Beta vulgaris) leaves. Physiologia Plantarum 112, 31-38. doi: 10.1034/j.1399-3054.2001.1120105.x.

Lott JNA, West MM. 2001. Elements present in mineral nutrient reserves in dry Arabidopsis thaliana seeds of wild type and pho1, pho2, and man1 mutants. Canadian Journal of Botany 79, 1292-1296.

Lundström M, Leino MW, Hagenblad J. 2017. Evolutionary history of the NAM-B1 gene in wild and domesticated tetraploid wheat. BMC Genetics 18:118

Lynch S V, Pedersen 0. 2016. The Human Intestinal Microbiome in Health and Disease. New England Journal of Medicine 375, 2369-2379.

Majeed A, Muhammad Z, Ahmad H. 2018. Plant growth promoting bacteria: role in soil improvement, abiotic and biotic stress management of crops. Plant Cell Reports 37, 1599-1609.

Mari S, Bailly C, Thomine S. 2020. Handing off iron to the next generation: how does it get into seeds and what for? Biochemical Journal 477, 259-274.

Martinez-Medina A, Flors V, Heil M, Mauch-Mani B, Pieterse CMJ, Pozo MJ, Ton J, van Dam NM, Conrath U. 2016. Recognizing plant defense priming. Trends in Plant Science 21, 818-822.

Maruta T, Ichikawa Y, Mieda T, Takeda T, Tamoi M, Yabuta Y, Ishikawa T, Shigeoka S. 2010. The contribution of Arabidopsis homologs of L-Gulono-1,4-lactone Oxidase to the biosynthesis of ascorbic acid. Bioscience, Biotechnology, and Biochemistry 74, 1494-1497. DOI:10.1271/bbb.100157.

Marzorati F, Vigani G, Morandini P, Murgia I. 2021. Formate dehydrogenase contributes to the early Arabidopsis thaliana responses against Xanthomonas campestris pv campestris infection. Physiological and Molecular Plant Pathology 114, 101633. https://doi.org/10.1016/j.pmpp.2021.101633.

Mendoza-Cózatl DG, Gokul A, Carelse MF, Jobe TO, Long TA. and Keyster M. 2019. Keep talking: crosstalk between iron and sulfur networks fine-tunes growth and development to promote survival under iron limitation. Journal of Experimental Botany 70, 4197-4210. doi: 10.1093/jxb/erz290 
Miethke M, Marahiel MA. 2007. Siderophore-based iron acquisition and pathogen control. Microbiology and Molecular Biology Reviews 71, 413-451.

Moore KL, Rodríguez-Ramiro I, Jones ER, et al. 2018. The stage of seed development influences iron bioavailability in pea (Pisum sativum L.). Scientific Reports 8(1):6865. doi:10.1038/s41598-018-25130-3.

Morrissey J, Baxter IR, Lee J, Li L, Lahner B, Grotz N, Kaplan J, Salt DE, Guerinot ML. 2009. The ferroportin metal efflux proteins function in iron and cobalt homeostasis in Arabidopsis. Plant Cell 21, 3326-3338.

Murgia I, Delledonne M, Soave C. 2002. Nitric oxide mediates iron-induced ferritin accumulation in Arabidopsis. The Plant Journal 30, 521-528.

Murgia I, Vazzola V, Tarantino D, Cellier F, Ravet K, Briat JF, Soave C. 2007. Knock-out of ferritin AtFer1 causes earlier onset of age-dependent leaf senescence in Arabidopsis. Plant Physiology and Biochemistry 45, 898-907. doi: 10.1016/j.plaphy.2007.09.007.

Murgia I, Tarantino D, Soave C, Morandini P. 2011. The Arabidopsis CYP82C4 expression is dependent on Fe availability and the circadian rhythm and it correlates with genes involved in the early Fe-deficiency response. Journal of Plant Physiology 168, 894-902.

Murgia I, Arosio P, Tarantino D, Soave C. 2012. Biofortification for combating "hidden hunger" for iron. Trends in Plant Science. 17, 47-55. DOI: 10.1016/j.tplants.2011.10.003.

Murgia I, De Gara L, Grusak M. 2013. Biofortification: how can we exploit plant science to reduce micronutrient deficiencies? Frontiers in Plant Science 4:429. doi: 10.3389/fpls.2013.00429.

Murgia I, Vigani G, Di Silvestre D, Mauri P, Rossi R, Bergamaschi A, Frisella M, Morandini P. 2020. Formate dehydrogenase takes part in molybdenum and iron homeostasis and affects dark-induced senescence in plants. Journal of Plant Interactions 15, 386-397. Doi: 10.1080/17429145.2020.1836273.

Nascimento FX, Rossi MJ, Glick BR. 2018. Ethylene and 1-aminocyclopropane-1-carboxylate (ACC) in plantbacterial interactions. Frontiers in Plant Science 9, 1-17. 
Nihorimbere V, Ongena M, Smargiassi M, Thonart P. 2011. Beneficial effect of the rhizosphere microbial community for plant growth and health. Biotechnology, Agronomy and Society and Environment 15, 327337.

Osorio Vega NW. 2007. A review on beneficial effects of rhizosphere bacteria on soil nutrient availability and plant nutrient uptake. Revista Facultad Nacional de Agronomía Medellín 60, 3621-3643.

Ozturk L, Altintas G, Erdem H, Gokmen O O, Yazici, A, Cakmak, I. 2009. Localization of iron, zinc, and protein in seeds of spelt (Triticum aestivum ssp. spelta) genotypes with low and high protein concentration. UC Davis: https://escholarship.org/uc/item/08n1b60m.

Paasch BC, He SY. 2021. Toward understanding microbiota homeostasis in the plant kingdom. PLoS Pathogens 17, 1-8.

Palmer CM, Hindt MN, Schmidt H, Clemens S, Guerinot M L. 2013. MYB10 and MYB72 are required for growth under iron-limiting conditions. PLoS Genetics 9(11): e1003953. https://doi.org/10.1371/journal.pgen.1003953.

Pangesti N, Vandenbrande S, Pineda A, Dicke M, Raaijmakers JM, Van Loon JJA. 2017. Antagonism between two root-associated beneficial Pseudomonas strains does not affect plant growth promotion and induced resistance against a leaf-chewing herbivore. FEMS Microbiology Ecology 93, 1-8.

Pascale A, Proietti S, Pantelides IS, Stringlis IA. 2020. Modulation of the root microbiome by plant molecules: the basis for targeted disease suppression and plant growth promotion. Frontiers in Plant Science 10, 1741. DOI:10.3389/fpls.2019.01741.

Peng JH, Sun DF, Peng YL, Nevo E. 2013. Gene discovery in Triticum dicoccoides, the direct progenitor of cultivated wheats. Cereal Research Communications 41, 1-22.

Petit JM, Briat JF, Lobréaux S. 2001. Structure and differential expression of the four members of the Arabidopsis thaliana ferritin gene family. Biochemical Journal 359, 575-582. doi:10.1042/02646021:3590575 
Pieterse CMJ, Leon-Reyes A, Van Der Ent S, Van Wees SCM. 2009. Networking by small-molecule hormones in plant immunity. Nature Chemical Biology 5, 308-316.

Pieterse CMJ, Zamioudis C, Berendsen RL, Weller DM, Van Wees SCM, Bakker PAHM. 2014. Induced systemic resistance by beneficial microbes. Annual Review of Phytopathology 52, 347-375.

Pieterse CMJ, Berendsen RL, Jonge R De, Stringlis IA. 2020. Pseudomonas simiae WCS417 : star track of a model beneficial rhizobacterium. Plant Soil 461, 245-263.

Pigna G, Morandini P. 2017. Domestication of New Species, in Pilu R., Gavazzi G. (eds.) More Food: Road to Survival, Bentham Science, Sharjah.

Pontiggia D, Benedetti M, Costantini S, De Lorenzo G, Cervone F. 2020. Dampening the DAMPs: how plants maintain the homeostasis of cell wall molecular patterns and avoid hyper-immunity. Frontiers in Plant Science 11:613259. doi: 10.3389/fpls.2020.613259.

Pottier M, Masclaux Daubresse C, Yoshimoto K, Thomine S. 2014. Autophagy as a possible mechanism for micronutrient remobilization from leaves to seeds. Frontiers in Plant Science 5, 11.DOI:10.3389/fpls.2014.00011.

Pottier M, Dumont J, Masclaux-Daubresse C, Thomine S. 2019. Autophagy is essential for optimal translocation of iron to seeds in Arabidopsis. Journal of Experimental Botany 70, 859-869. doi.org/10.1093/jxb/ery388

Pozo MJ, Azcón-Aguilar C. 2007. Unraveling mycorrhiza-induced resistance. Current Opinion in Plant Biology 10, 393-398.

Rajniak J, Giehl RF, Chang E, Murgia I, von Wirén N, Sattely ES. 2018. Biosynthesis of redox-active metabolites in response to iron deficiency in plants. Nature Chemical Biology 14, 442-450. doi:10.1038/s41589-018-0019-2.

Ramirez L, Simontacchi M, Murgia I, Zabaleta E, Lamattina L. 2011. Nitric Oxide, Nitrosyl Iron complexes, ferritin and frataxin: a well equiped team to preserve plant iron homeostasis. Plant Science 181, 582-592. 
Ravanbakhsh M, Sasidharan R, Voesenek LACJ, Kowalchuk GA, Jousset A. 2018. Microbial modulation of plant ethylene signaling: ecological and evolutionary consequences. Microbiome 6, 52.

Ravet K, Touraine B, Boucherez J, Briat JF, Gaymard F, Cellier F. 2009a. Ferritins control interaction between iron homeostasis and oxidative stress in Arabidopsis. Plant Journal 57, 400-412. doi: 10.1111/j.1365-313X.2008.03698.x.

Ravet K, Touraine B, Kim SA, Cellier F, Thomine S, Guerinot ML, Briat JF, Gaymard F. 2009b. PostTranslational Regulation of AtFER2 Ferritin in Response to Intracellular Iron Trafficking during Fruit Development in Arabidopsis. Molecular Plant 2, 1095-1106. https://doi.org/10.1093/mp/ssp041.

Ravet K, Reyt G, Arnaud N, Krouk G, El-Batoul D, Boucherez J, Briat JF, Gaymard F. 2012. Iron and ROS control of the DownSTream mRNA decay pathway is essential for plant fitness. The EMBO Journal 31, 175-186.

Rellán-Álvarez R, Abadía J, Álvarez-Fernández A. 2008. Formation of metal-nicotianamine complexes as affected by $\mathrm{pH}$, ligand exchange with citrate and metal exchange. A study by electrospray ionization timeof-flight mass spectrometry. Rapid Communications in Mass Spectrometry 22, 1553-1562.

Rellán-Álvarez R, Giner-Martínez-Sierra J, Orduna J, Orera I, Rodríguez-Castrillón JA, García-Alonso Jl, Abadía J, Álvarez-Fernández A. 2010. Identification of a tri-iron(III), tri-citrate complex in the xylem sap of iron-deficient tomato resupplied with iron: new insights into plant iron long-distance transport. Plant and Cell Physiology 51, 91-102, https://doi.org/10.1093/pcp/pcp170

Reyt G, Boudouf S, Boucherez J, Gaymard F, Briat JF. 2015. Iron-and ferritin-dependent reactive oxygen species distribution: impact on Arabidopsis root system architecture. Molecular Plant 8, 439-453.

Riaz N, Guerinot ML. 2021. All together now: regulation of the iron deficiency response. Journal of Experimental Botany 72,2045-2055. doi: 10.1093/jxb/erab003

Ricachenevsky FK, Menguer PK, Sperotto RA. 2013. kNACking on heaven's door: how important are NAC transcription factors for leaf senescence and $\mathrm{Fe} / \mathrm{Zn}$ remobilization to seeds? Frontiers in Plant Science 4:226. doi: 10.3389/fpls.2013.00226. 
Robe, K, Conejero G, Gao F, Lefebvre-Legendre L, Sylvestre-Gonon E, Rofidal V, Hem S, Rouhier N, Barberon M, Hecker A, Gaymard F, Izquierdo E, Dubos C. 2021a. Coumarin accumulation and trafficking in Arabidopsis thaliana: a complex and dynamic process. New Phytologist 229, 2062-2079 doi: 10.1111/nph.17090.

Robe K, Izquierdo E, Vignols F, Rouached H, Dubos C. 2021b. The Coumarins: secondary metabolites playing a primary role in plant nutrition and health. Trends in Plant Science 26, 248-259. https://doi.org/10.1016/j.tplants.2020.10.008

Romera FJ, García MJ, Lucena C, Martínez-Medina A, Aparicio MA, Ramos J, Alcántara E, Angulo M, Pérez-Vicente R. 2019. Induced systemic resistance (ISR) and Fe deficiency responses in dicot plants. Frontiers in Plant Science 10, 1-17.

Roschzttardtz H, Conéjéro G, Curie C, Mari, S. 2009. Identification of the endodermal vacuole as the iron storage compartment in the Arabidopsis embryo. Plant Physiology 151, 1-10. doi: 10.1104/pp.109.144444.

Roschzttardtz H, Gaymard F, Dubos C. 2020. Transcriptional regulation of iron distribution in seeds: a perspective. Frontiers in Plant Science 11:725. doi: 10.3389/fpls.2020.00725.

Sánchez-Cañizares C, Jorrín B, Poole PS, Tkacz A. 2017. Understanding the holobiont: the interdependence of plants and their microbiome. Current Opinion in Microbiology 38, 188-196.

Sasse J, Martinoia E, Northen T. 2018. Feed your friends: do plant exudates shape the root microbiome? Trends in Plant Science 23, 25-41.

Schmid NB, Giehl RFH, Doll S, Mock HP, Strehmel N, Scheel D, Kong XL, Hider RC, von Wiren N. 2014. Feruloyl-CoA 6'hydroxylase1-dependent coumarins mediate iron acquisition from alkaline substrates in Arabidopsis. Plant Physiology 164, 160-172.

Schulz-Bohm K, Martín-Sánchez L, Garbeva P. 2017. Microbial volatiles: small molecules with an important role in intra- and inter-kingdom interactions. Frontiers in Microbiology 8, 2484 DOI:10.3389/fmicb.2017.02484. 
Schwacke R, Schneider A, Van Der Graaff E, Fischer K, Catoni E, Desimone M, Frommer WB, Flügge UI, Kunze R. 2003. ARAMEMNON, a novel database for Arabidopsis integral membrane proteins. Plant Physiology 131, 16-26.

Schwarz B, Bauer P. 2020. FIT, a regulatory hub for iron deficiency and stress signaling in roots, and FITdependent and -independent gene signatures, Journal of Experimental Botany 71, 1694-1705, https://doi.org/10.1093/jxb/eraa012.

Schwertmann U. 1991. Solubility and dissolution of iron oxides. Plant and Soil 130, 1-25. www.jstor.org/stable/42937281.

Sharma SS, Dietz KJ, Mimura T. 2016. Vacuolar compartmentalization as indispensable component of heavy metal detoxification in plants. Plant, Cell and Environment 39, 1112-1126. doi: 10.1111/pce.12706.

Sharma S, Lavale SA, Nimje C, Singh S. 2020. Characterization and identification of annual wild Cicer species for seed protein and mineral concentrations for chickpea improvement. Crop Science 61, 315-319.

Shen C, Yang Y, Liu K, Zhang L, Guo H, Sun T, Wang H. 2016. Involvement of endogenous salicylic acid in iron-deficiency responses in Arabidopsis. Journal of Experimental Botany 67, 4179-4193.

Shi R, Weber G, Köster J, Reza-Hajirezaei M, Zou C, Zhang F, Wirén NV. 2012. Senescence-induced iron mobilization in source leaves of barley (Hordeum vulgare) plants. New Phytologist 195, 372-383.

Simon JC, Marchesi JR, Mougel C, Selosse MA. 2019. Host-microbiota interactions: from holobiont theory to analysis. Microbiome 7, 1-5.

Sisó-Terraza P, Rios JJ, Abadía J, Abadía A, Álvarez-Fernández A. 2016. Flavins secreted by roots of irondeficient Beta vulgaris enable mining of ferric oxide via reductive mechanisms. New Phytologist 209, 733745. doi: 10.1111/nph.13633.

Smirnoff N. 2018. Ascorbic acid metabolism and functions: a comparison of plants and mammals. Free Radical Biology \& Medicine 122,116-129. doi: 10.1016/j.freeradbiomed.2018.03.033. 
Sreenivasulu N, Wobus U. 2013. Seed-development programs: a systems biology-based comparison between dicots and monocots. Annual Review Plant Biology 64, 189-217.

Srivastava AK, Kumar JK, Suprasanna P. 2021. Seed 'primeomics': plants memorize their germination under stress. Biological Reviews. doi: 10.1111/brv.12722.

Stassen MJJ, Hsu SH, Pieterse CMJ, Stringlis IA. 2021. Coumarin communication along the microbiomeroot-shoot axis. Trends in Plant Science 26, 169-183.

Stringlis IA, Proietti S, Hickman R, Van Verk MC, Zamioudis C, Pieterse CMJ. 2018a. Root transcriptional dynamics induced by beneficial rhizobacteria and microbial immune elicitors reveal signatures of adaptation to mutualists. Plant Journal 93, 166-180.

Stringlis IA, Yu K, Feussner K, De Jonge R, Van Bentum S, Van Verk MC, Berendsen RL, Bakker PAHM, Feussner I, Pieterse CMJ. 2018b. MYB72-dependent coumarin exudation shapes root microbiome assembly to promote plant health. Proceedings of the National Academy of Sciences of the United States of America 115, E5213-E5222.

Stringlis IA, De Jonge R, Pieterse CMJ. 2019. The age of coumarins in plant-microbe interactions. Plant and Cell Physiology 60, 1405-1419.

Sun Y, Li JQ, Yan JY, Yuan JJ, Li GX, Wu YR, Xu JM, Huang RF, Harberd NP, Ding ZJ, Zheng SJ. 2020. Ethylene promotes seed iron storage during Arabidopsis seed maturation via ERF95 transcription factor. Journal of Integrative Plant Biology 62,1193-1212. doi: 10.1111/jipb.12986.

Sun L, Wei YQ, Wu KH, Yan JY, Xu JN, Wu YR, Li GX, Xu JM, Harberd NP, Ding ZJ, Zheng SJ. 2021. Restriction of iron loading into developing seeds by a YABBY transcription factor safeguards successful reproduction in Arabidopsis. Molecular Plant 14, 1624-1639. doi.org/10.1016/j.molp.2021.06.005.

Takahashi M, Nozoye T, Kitajima N. et al. 2009. In vivo analysis of metal distribution and expression of metal transporters in rice seed during germination process by microarray and $\mathrm{X}$-ray fluorescence imaging of Fe, Zn, Mn, and Cu. Plant Soil 325, 39. https://doi.org/10.1007/s11104-009-0045-7

Tarantino D, Petit JM, Lobreaux S, Briat JF, Soave C, Murgia I. 2003. Differential involvement of the IDRS 
cis-element in the developmental and environmental regulation of the AtFer1 ferritin gene from Arabidopsis. Planta 217, 709-716.

Tarantino D, Casagrande F, Soave C, Murgia I. 2010a. Knocking out of the mitochondrial AtFer4 ferritin does not alter response of Arabidopsis plants to abiotic stresses. Journal of Plant Physiology 167, 453-460.

Tarantino D, Santo N, Morandini P, Casagrande F, Braun HP, Heinemeyer J, Vigani G, Soave C, Murgia I. 2010b. AtFer4 ferritin is a determinant of iron homeostasis in Arabidopsis thaliana heterotrophic cells. Journal of Plant Physiology 167, 1598-1605.

Tato L, Lattanzio V, Ercole E, Dell’Orto M, Sorgonà A, Linsalata V, Salvioli di Fossalunga A, Novero M, Astolfi S, Abenavoli MR, Murgia I, Zocchi G, Vigani G. 2021. Plasticity, exudation and microbiomeassociation of the root system of Pellitory-of-the-wall plants grown in environments impaired in iron availability. Plant Physiology and Biochemistry 168, 27-42.

https://doi.org/10.1016/j.plaphy.2021.09.040.

Trivedi P, Leach JE, Tringe SG, Sa T, Singh BK. 2020. Plant-microbiome interactions: from community assembly to plant health. Nature Reviews Microbiology 18, 607-621.

Tsai HH, Schmidt W. 2017. Mobilization of iron by plant-borne coumarins. Trends in Plant Science 22, 538548.

Tsai HH, Rodrıguez-Celma J, Lan P, Wu YC, Velez-Bermudez IC, Schmidt W. 2018. Scopoletin 8hydroxylase-mediated fraxetin production is crucial for iron mobilization. Plant Physiology 177, 194-207.

Tsai HH, Schmidt W. 2020. pH-dependent transcriptional profile changes in iron-deficient Arabidopsis roots. BMC Genomics 21:694. https://doi.org/10.1186/s12864-020-07116-6.

Uauy C, Distelfeld A, Fahima T, Blechl A, Dubcovsky J. 2006. A NAC gene regulating senescence improves grain protein, zinc, and iron content in wheat. Science 314, 1298-1301.

Vandenkoornhuyse P, Quaiser A, Duhamel M, Le Van A, Dufresne A. 2015. The importance of the microbiome of the plant holobiont. New Phytologist 206, 1196-1206. 
Van der Ent S, Van Wees SCM, Pieterse CMJ. 2009. Jasmonate signaling in plant interactions with resistance-inducing beneficial microbes. Phytochemistry 70, 1581-1588.

Van Loon LC, Bakker PAHM, Pieterse CMJ. 1998. Systemic resistance induced by rhizosphere bacteria. Annual Review of Phytopathology 36, 453-483.

Van Loon LC. 2007. Plant responses to plant growth-promoting rhizobacteria. European Journal of Plant Pathology 119, 243-254.

Verbon EH, Trapet PL, Stringlis IA, Kruijs S, Bakker PAHM, Pieterse CMJ. 2017. Iron and Immunity. Annual Review of Phytopathology 55, 355-375.

Verbon EH, Trapet PL, Kruijs S, Temple-Boyer-Dury C, Rouwenhorst TG, Pieterse CMJ. 2019. Rhizobacteria-mediated activation of the Fe deficiency response in Arabidopsis roots: impact on Fe status and signaling. Frontiers in Plant Science 10, 1-12.

Vigani G, Morandini P, Murgia I. 2013. Searching iron sensors in plants by exploring the link among 2'-OGdependent dioxygenases, the iron deficiency response and metabolic adjustments occurring under iron deficiency. Frontiers in Plant Science 4, 169.

Vigani G, Faoro F, Ferretti AM, Cantele F, Maffi, D, Marelli, M, Maver M, Murgia I, Zocchi G. 2015. Threedimensional reconstruction, by TEM tomography, of the ultrastructural modifications occurring in Cucumis sativus L. mitochondria under Fe deficiency. PLoS One 10: e0129141.

Vigani G, Bashir K, Ishimaru Y, Lehmann M, Casiraghi, FM, Nakanishi H, Seki M, Geigenberger P, Zocchi G, Nishizawa NK. 2016. Knocking down mitochondrial iron transporter (MIT) reprograms primary and secondary metabolism in rice plants. Journal of Experimental Botany 67, 1357-1368.

Vigani G, Di Silvestre D, Agresta AM, Donnini S, Mauri P, Gehl C, Bittner F, Murgia I. 2017. Molybdenum and iron mutually impact their homeostasis in cucumber (Cucumis sativus) plants. New Phytologist 213, 1222- 124. 
Vigani G, Hanikenne M. 2018. "Metal homeostasis in plant mitochondria," in Logan DC, ed. Annual Plant Reviews. Chichester: John Wiley \& Sons, Ltd, 111-142. doi: 10.1002/9781119312994.apr0547

Vigani G, Murgia I. 2018. Iron-requiring enzymes in the spotlight of oxygen. Trends in Plant Science. 23, 874-882.

Vigani G, Solti A, Thomine S, Philippar K. 2019. Essential and detrimental-an update on intracellular iron trafficking and homeostasis. Plant and Cell Physiology 1-20. doi:10.1093/pcp/pcz091

Voges MJEEE, Bai Y, Schulze-Lefert P, Sattely ES. 2019. Plant-derived coumarins shape the composition of an Arabidopsis synthetic root microbiome. Proceedings of the National Academy of Sciences of the United States of America 116, 12558-12565.

von Wiren N, Klair S, Bansal S, Briat JF, Khodr H, Shioiri T, Leigh RA, Hider RC. 1999. Nicotianamine chelates both Felll and Fell. Implications for metal transport in plants. Plant Physiology 119, 1107-1114. doi: 10.1104/pp.119.3.1107.

Wairich A, de Oliveira BHN, Arend EB, Duarte GL, Ponte LR, Sperotto RA, Ricachenevsky FK, Fett JP. 2019. The combined strategy for iron uptake is not exclusive to domesticated rice (Oryza sativa). Scientific Reports 9:16144.

Wang HY, Klatte M, Jakoby M, Bäumlein H, Weisshaar B, Bauer P. 2007. Iron deficiency-mediated stress regulation of four subgroup Ib BHLH genes in Arabidopsis thaliana. Planta 226, 897-908.

Wang N, Cui Y, Liu Y, Fan H, Du J, Huang Z, Yuan Y, Wu H, Ling HQ. 2013. Requirement and functional redundancy of $\mathrm{Ib}$ subgroup bHLH proteins for iron deficiency responses and uptake in Arabidopsis thaliana. Molecular Plant 6, 503-513. doi: 10.1093/mp/sss089.

Waters BM, Chu HH, DiDonato RJ, Roberts LA, Eisley RB, Lahner B, Salt DE, Walker EL. 2006. Mutations in Arabidopsis Yellow Stripe-Like1 and Yellow Stripe-Like3 reveal their roles in metal ion homeostasis and loading of metal ions in seeds. Plant Physiology 141, 1446-1458.

Waters BM, Sankaran RP. 2011. Moving micronutrients from the soil to the seeds. Genes and physiological processes from a biofortification perspective. Plant Science 180, 562-574. 
Weber H, Borisjuk L, Wobus U. 2005. Molecular physiology of legume seed development. Annual Review Plant Biology 56, 253-279.

Yokosho K, Yamaji N, Ma JF. 2016. OsFRDL1 expressed in nodes is required for distribution of iron to grains in rice. Journal of Experimental Botany 67, 5485-5494.

Yu K, Stringlis IA, van Bentum S, de Jonge R, Snoek BL, Pieterse CMJ, Bakker PAHM, Berendsen RL. 2021. Transcriptome signatures in Pseudomonas simiae WCS417 shed light on role of root-secreted coumarins in Arabidopsis-mutualist communication. Microorganisms 9, 1-15.

Zamioudis C, Hanson J, Pieterse CMJ. 2014. B-Glucosidase BGLU42 is a MYB72-dependent key regulator of rhizobacteria-induced systemic resistance and modulates iron deficiency responses in Arabidopsis roots. New Phytologist 204, 368-379.

Zamioudis C, Korteland J, Van Pelt JA, et al. 2015. Rhizobacterial volatiles and photosynthesis-related signals coordinate MYB72 expression in Arabidopsis roots during onset of induced systemic resistance and iron-deficiency responses. Plant Journal 84, 309-322.

Zancani M, Peresson M, Biroccio A, Federici G, Urbani A, Murgia I, Soave C, Micali F, Vianello A, Macrì F. 2004. Evidence for the presence of ferritin in plant mitochondria. European Journal of Biochemistry 271, 3657-3664.

Zhai Z, Gayomba SR, Jung HI, et al. 2014. OPT3 is a phloem-specific iron transporter that is essential for systemic iron signaling and redistribution of iron and cadmium in Arabidopsis. Plant Cell 26, 2249-2264.

Zhang Y, Xu YH, Yi HY, Gong JM. 2012. Vacuolar membrane transporters OsVIT1 and OsVIT2 modulate iron translocation between flag leaves and seeds in rice. The Plant Journal 72,400-410. doi: 10.1111/j.1365313X.2012.05088.x.

Ziegler J, Schmidt S, Strehmel N, Scheel D, Abel S. 2017. Arabidopsis transporter ABCG37/PDR9 contributes primarily highly oxygenated coumarins to root exudation. Scientific Reports 7, 3704. https://doi.org/10.1038/s41598-017-03250-6. 
Zipfel C. 2008. Pattern-recognition receptors in plant innate immunity. Current Opinion in Immunology 20, 10-16. 


\section{BOX 1: Plant immune responses}

Plants are continuously exposed to the attacks of several pathogens and pests during their life; they have therefore developed diverse strategies to perceive assaulters and mount immune responses. Once plants come in contact with microbes, they firstly locally recognize characteristic features of microorganisms (e.g., lipopolysaccharides, glycoproteins, flagellin and chitin), known as microbeassociated molecular patterns (MAMPs), or pathogen-associated molecular patterns (PAMPs) when produced by pathogens. These molecules are perceived through pattern-recognition receptors (PRRs), starting downstream signalling pathways that activate the so-called 'MAMP-triggered immunity' (MTI) or 'PAMP-triggered immunity' (PTI) (Zipfel, 2008; Pieterse et al., 2009; Choi et al., 2016; De Lorenzo et al., 2018; Pontiggia et al., 2020). A secondary major immune response, known as 'effector-triggered immunity' (ETI), is also activated when specific plant resistance proteins are produced to react against pathogens' molecules (i.e., the effectors), which are introduced in plant host cells to suppress MTI/PTI (Cui et al., 2015). These two immune defense responses partially overlap, because of the accumulation of pathogenesis-related (PR) proteins that help in plant resistance. Once the defense response has been turned on at the site of the infection, a 'Systemic Acquired Resistance' (SAR), is frequently activated far away from the site of the attack to defend undamaged tissues. SAR activation is associated with an increase of the hormone salicylic acid (SA), both at the site of the infection and in distant plant organs (Fu and Dong, 2013; Klessig et al., 2018). Beneficial microorganisms in soils can stimulate a systemic immunity similar to SAR, known as 'Induced Systemic Resistance' (ISR) (Van Loon et al., 1998; Pozo and Azcón-Aguilar, 2007; Pieterse et al., 2014). In ISR, root microbiota can elevate the level of disease resistance against different pathogenic threats, activating various phytohormone signalling pathways and transferring this defense message to distant plant tissues. Jasmonic acid (JA) and ethylene (ET) are the two hormones involved in ISR signalling (Van der Ent et al., 2009). Similar to SAR, ISR is activated only upon an external stress factor, so that plants can save resources; this strategy is known as 'defense priming', allowing plants to alert their immune system for future pathogen or pest attacks, thus avoiding a direct activation of defense responses. The main differences between the two systemic plant immunities are the 'priming stimulus' triggering the defense priming and the hormones involved (Conrath et al., 2015; Martinez-Medina et al., 2016). ISR has been described for several PGPR such as Pseudomonas spp., Bacillus spp. and Serratia spp.; Pseudomonas and Bacillus genera often represent the dominant group in the rhizosphere. ISR has been also described for PGPF, such as Trichoderma spp., Fusarium spp., Serendipita spp., and arbuscular mycorrhizal fungi AMF (Nihorimbere et al., 2011; Pascale et al., 2020). Nevertheless, perturbations of this 'core' root microbiota may be helpful for plants, since variations in microbial genera abundance in the rhizosphere may help plants to react against different biotic and abiotic stresses (Paasch and $\mathrm{He}$, 2021 and references therein). 


\section{Figure legends}

\section{Figure 1}

Schematic model of the interactions among root Fe uptake mechanisms, the microbiota present in the rhizosphere (in particular WCS417) and plant immunity responses. A Strategy I root cell and its surrounding rhizosphere are represented. Red arrows show the cascade of events occurring during Fe deficiency response (thick arrows for transport/movement; thin arrows for signalling), which are regulated by FIT1, MYB72/MYB10, BGLU72, and leading to i) Fe uptake through the coordinated activity of AHA2, FRO2 and IRT1, ii) biosynthesis of coumarins through the phenylpropanoid pathway and their release into the rhizosphere through PDR9 transporter. Both coumarins and protons act on the pool of poorly soluble Fe(hydroxy)oxides. Pseudomonas simiae WCS417, as well as other beneficial microorganisms, can release bacterial siderophores which also increase Fe solubility from the pool of $\mathrm{Fe}$ (hydroxy)oxides in the soil. Blue arrows indicate immune response pathways, such that one triggered by WCS417 and leading to suppression of MAMP-triggered immunity (evasion of host immunity), as well as those triggered by WCS417 siderophores and leading to suppression of plant pathogens. Purple arrows indicate overlapping pathways of Fe deficiency responses and immune responses; WCS417 induction of Fe deficiency responses and phenylpropanoid pathway and dependence of such induction on WCS417 concentration threshold are represented, as well as the effects of coumarins on WCS417 and pathogens. PM: plasma membrane. For further details regarding biosynthesis, transport and biological activity of coumarins refer to Robe et al. (2021b).

\section{Figure 2}

Formate dehydrogenase (FDH) is a protein hub for Fe plant nutrition and a node of the multiple interactions between $\mathrm{Fe}$ homeostasis and plant responses to abiotic and biotic stresses. Experiments conducted on roots and on aerial parts of $A$. thaliana plants (shown in the center) support the model of $\mathrm{FDH}$ as a hub of plant Fe nutrition, in a loop regulation with Fe homeostasis and responses against abiotic stresses. A leaf hydathode under physiological conditions (upper right), or exposed to Xanthomonas campestris campestris Xcc attack (lower right) are represented. Inhibition of FDH promoter activity by Xcc would lead to a local increase in formate concentration; such change in formate concentration, in turn, might act as a possible signal for plant defense responses to pathogen's entry (see main text and cited references for details).

\section{Figure 3}

Proposed model of Fe uptake in developing embryos. An A.thaliana developing seed is shown, with its embryo at the bent cotyledon stage, endosperm and the cell layers of maternal origin forming the seed coat. The possible contribution of the L-gulono-1,4 $\gamma$-lactone oxidase GULLO2 to the ASC pool, for Fe(III) reduction into $\mathrm{Fe}(\mathrm{II})$ and its subsequent transport into the developing embryos, is reported with dashed arrows. The role of the GULLO2 reaction product $\mathrm{H}_{2} \mathrm{O}_{2}$ on the endosperm and on the seed coat composition is unknown. ASC, ascorbic acid. 


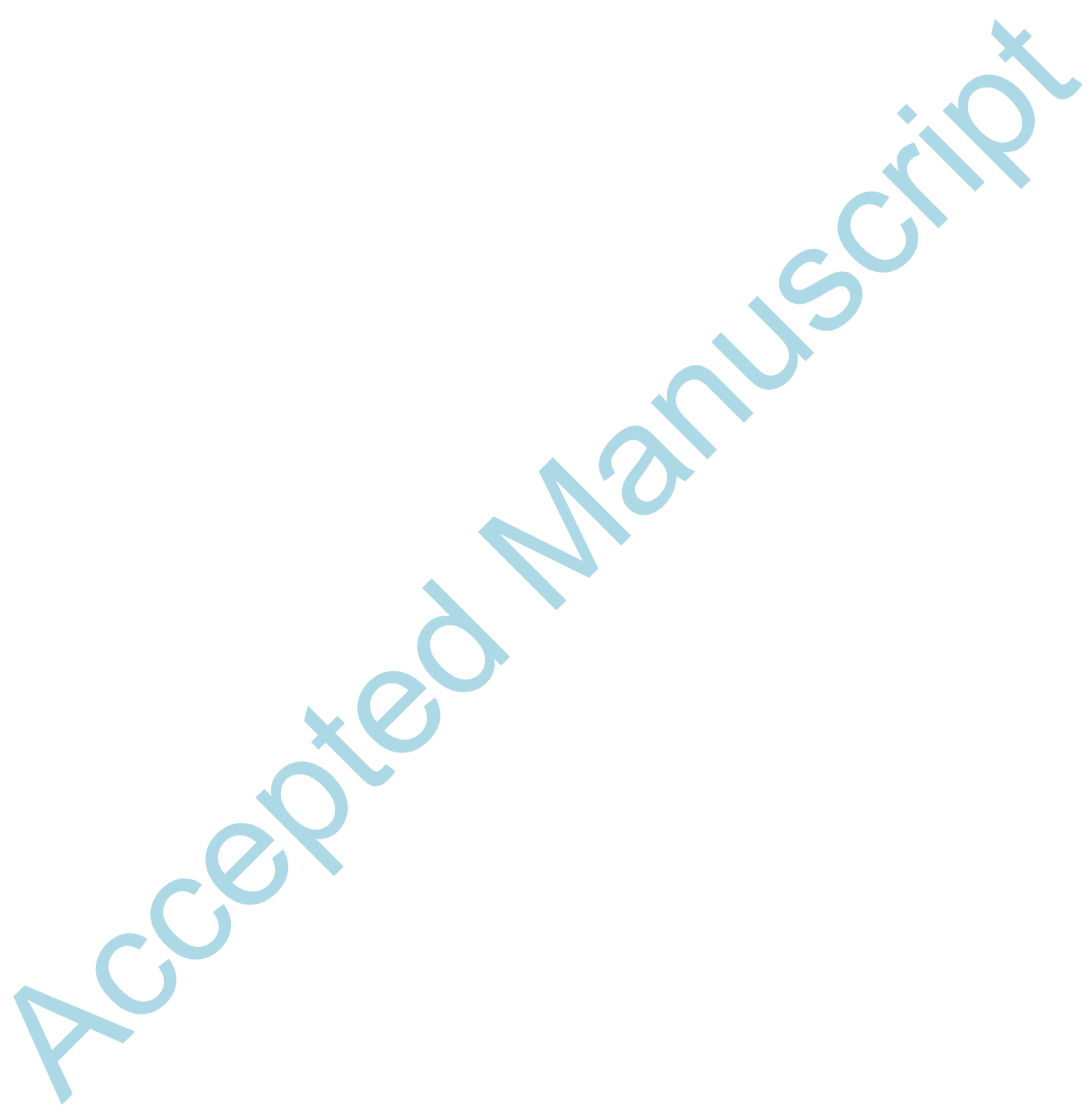


Figure 1

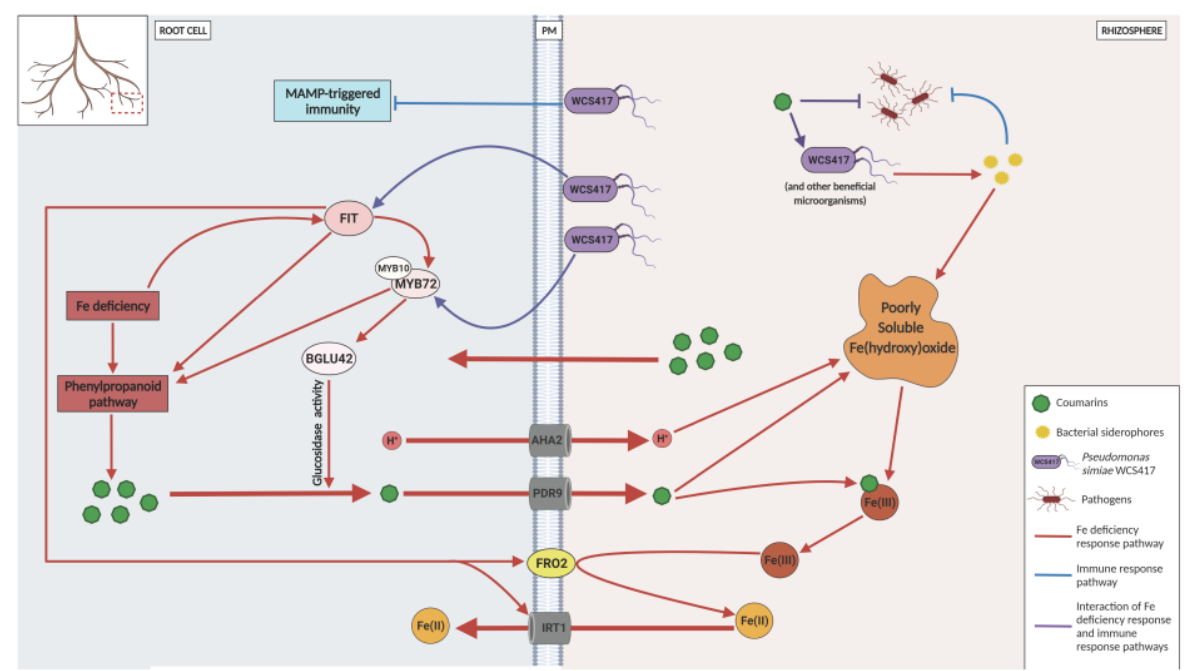

Figure 1

Schematic model of the interactions among root Fe uptake mechanisms, the microbiota present in the rhizosphere (in particular WCS417) and plant immunity responses. A Strategy I root cell and its surrounding rhizosphere are represented. Red arrows show the cascade of events occurring during Fe deficiency response (thick arrows for transport/movement; thin arrows for signalling), which are regulated by FIT1, MYB72/MYB10, BGLU72, and leading to i) Fe uptake through the coordinated activity of AHA2, FRO2 and IRT1, ii) biosynthesis of coumarins through the phenylpropano Pseudomonas simiae WCS417, as well as other beneficial microorganisms, can release bacterial siderophores which also increase Fe solubility from the pool of Fe(hydroxy)oxides in the soil. Pseudomonas simiae WCS417, as well as other beneficial microorganisms, can release bacterial siderophores which also increase Fe solubility from the pool of Fe(hydroxy)oxides in the soil. Blue arrows indicate immune response pathways, such that one triggered by WCS417 and leading to suppression of MAMP-triggered immunity (evasion of host immunity), as well as those
triggered by WCS417 siderophores and leading to suppression of plant pathogens. Purple arrows indicate overlapping pathways of Fe deficiency responses and immune responses; WCS417 triggered by WCS417 siderophores and leading to suppression of plant pathogens. Purple arrows indicate overlapping pathways of Fe deficiency responses and immune responses; WCS417
induction of Fe deficiency responses and phenylpropanoid pathway and dependence of such induction on WCS417 concentration threshold are represented, as well as the effects of coumarins on WCS417 and pathogens. PM: plasma membrane. For further details regarding biosynthesis, transport and biological activity of coumarins refer to Robe et al. (2021b). 


\section{Figure 2}

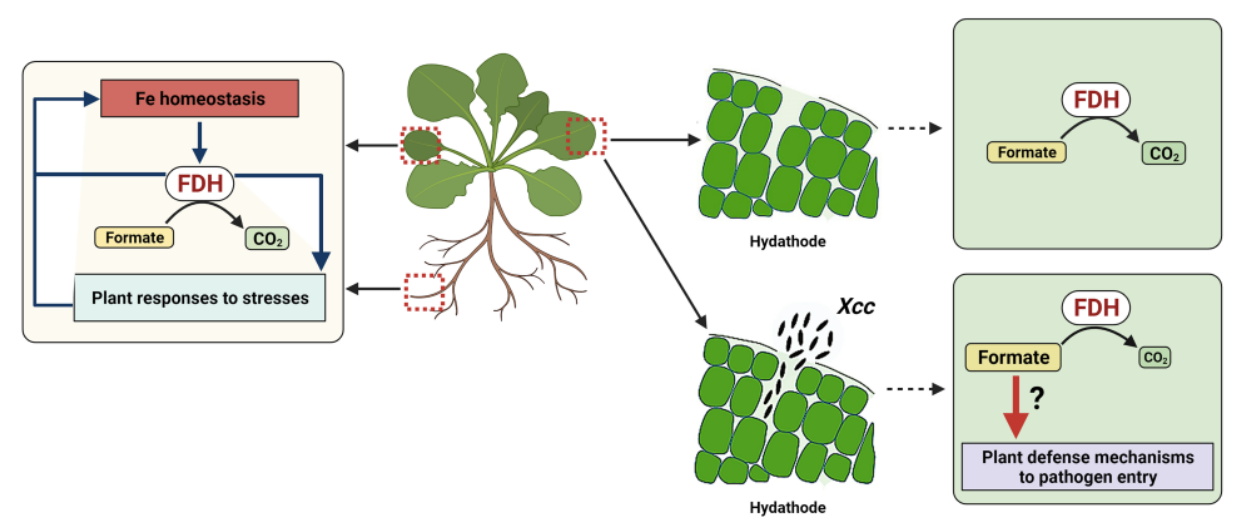

Figure 2

Formate dehydrogenase (FDH) is a protein hub for Fe plant nutrition and a node of the multiple interactions between Fe homeostasis and plant responses to abiotic and biotic stresses. Experiments conducted on roots and on aerial parts of $A$. thaliana plants (shown in the center) support the model of FDH as a hub of plant Fe nutrition, in a loop regulation with Fe homeostasis and responses against abiotic stresses. A leaf hydathode under physiological conditions (upper right), or exposed to

Xanthomonas campestris campestris Xcc attack (lower right) are represented. Inhibition of FDH promoter activity by Xcc would lead to a local increase in formate concentration; such change in formate concentration, in turn, might act as a possible signal for plant defense responses to pathogen's entry (see main text and cited references for details). 
Figure 3

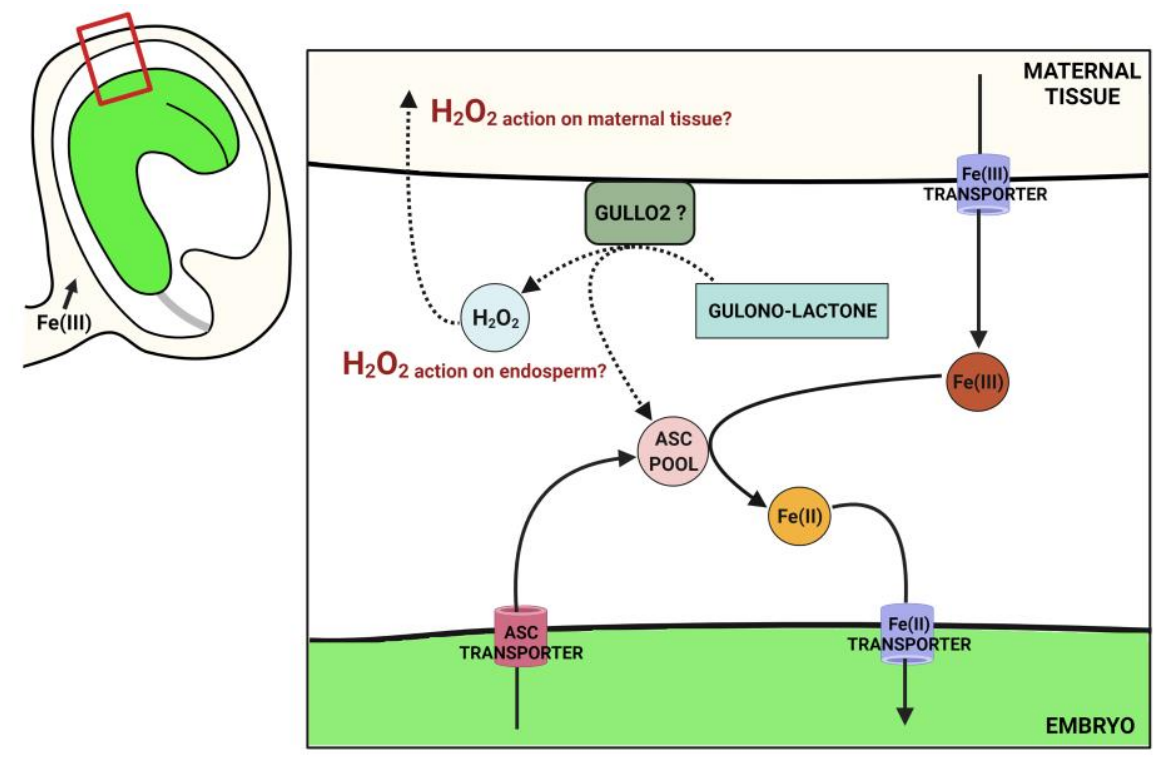

Figure 3

Proposed model of Fe uptake in developing embryos. An A.thaliana developing seed is shown, with its embryo at the bent cotyledon stage, endosperm and the cell layers of maternal origin forming the seed coat. The possible contribution of the L-gulono-1,4 $\gamma$-lactone oxidase GULLO2 to the ASC pool, for Fe(III) reduction into $\mathrm{Fe}(\mathrm{II})$ and its subsequent transport into the developing embryos, is reported with dashed arrows. The role of the $\mathrm{GULLO}_{2}$ reaction product $\mathrm{H}_{2} \mathrm{O}_{2}$ on the endosperm and on the seed coat composition is unknown. ASC, ascorbic acid. 